\title{
Electrical, Dielectric and Magnetic Properties of Mg2+ Doped Zn-Co-La Spinel Ferrites for High Microwave Frequency (5.7-13.4 GHz) Applications
}

\section{Muhammad Sajjad UI Hassan}

The University of Lahore

Nicola A Morley

The University of Sheffield

Syed Shahbaz Ali

The University of Lahore

Nasir Amin

Government College University Faisalabad

Aisha Bibi

Soochow University

Muhammad Imran Arshad (D miarshadgcuf@gmail.com )

Government College University Faisalabad https://orcid.org/0000-0002-8251-4229

Muhammad Ajaz Un Nabi

Government College University Faisalabad

Adnan Ali

Government College University Faisalabad

Khalid Mahmood

Government College University Faisalabad

Asma Aslam

Government College University Faisalabad

\section{Research Article}

Keywords: Spinel ferrites; SEM; Optical band gap; DC resistivity; VSM; High Microwave Frequency

Posted Date: May 11th, 2020

DOI: https://doi.org/10.21203/rs.3.rs-27162/v1

License: (c) (1) This work is licensed under a Creative Commons Attribution 4.0 International License.

Read Full License 


\title{
Electrical, Dielectric and Magnetic Properties of $\mathrm{Mg}^{2+}$ Doped $\mathrm{Zn}-\mathrm{Co}-\mathrm{La}$ Spinel Ferrites for High Microwave Frequency (5.7-13.4 GHz) Applications
}

\author{
M. S. Hasan ${ }^{\mathrm{a}}$, N. A. Morley ${ }^{\mathrm{b}}$, S.S. Alia ${ }^{\mathrm{a}}$ Nasir Amin ${ }^{\mathrm{c}}$, Aisha Bibi ${ }^{\mathrm{d}}$, M. Imran Arshad ${ }^{\mathrm{c} *}$ \\ ${ }^{a}$ Department of Physics, The University of Lahore, 1-kM Raiwind Road, Lahore, 54000, Pakistan. \\ ${ }^{b}$ Department of Materials Science and Engineering, The University of Sheffield, UK, S1 $3 J D$. \\ ${ }^{c}$ Department of Physics, Government College University, Faisalabad 38000, Pakistan. \\ ${ }^{d}$ Institute of Functional Nano \& Soft Materials (FUNSOM), Soochow University, Suzhou, Jiangsu \\ 215123, China.
}

*Corresponding Author: miarshadgcuf@gmail.com

\section{Abstract}

In the present research work, $\mathrm{Mg}^{2+}$ is inserted into $\mathrm{Zn}_{0.4} \mathrm{Co}_{0.6-\mathrm{x}} \mathrm{Mg}_{\mathrm{x}} \mathrm{Fe}_{1.9} \mathrm{La}_{0.1} \mathrm{O}_{4}(\mathrm{X}=0.00,0.15$, $0.30,0.45,0.60)$ soft ferrites prepared by the co-precipitation method. Structural, optical, vibrational, dielectric, electrical and magnetic properties were explored by XRD, SEM, UV, FTIR, SMU two probe, Raman, LCR and VSM methods respectively. XRD pattern revealed the formation of cubic spinel structure in all fabricated nanoferrites by the replacement of $\mathrm{Co}^{2+}$ ions with $\mathrm{Mg}^{2+}$ ions. UV-Vis also verified the substitution. The declining nature of optical band gap in the range of $2.65-1.85 \mathrm{eV}$ were observed by UV-Vis proving the $\mathrm{Mg}^{2+}$ ions replacement. Uniform spherical shaped nanoparticles were inspected by SEM investigation in form of microimages confirming the XRD outcomes. DC Electrical resistivity showed remarkable decreasing trend with the enhancement of $\mathrm{Mg}^{2+}$ concentration from $4.61 \times 10^{9}$ to $5.39 \times 10^{6} \Omega-\mathrm{cm}$ as $\mathrm{Mg}^{2+}$ is more conductive than $\mathrm{Co}^{2+}$. Five active phonon modes of Raman were examined by Raman spectroscopy. Dielectric parameters including dielectric losses and impedance demonstrated diminishing trends with the enrichment of $\mathrm{Mg}^{2+}$ contents. Various magnetic parameters such as magnetic moment $\left(\mu_{\mathrm{B}}\right)$, anisotropy constant $(\mathrm{K})$, initial permeability $\left(\mu_{\mathrm{i}}\right)$, Y-K angles $\left(\alpha_{\mathrm{y}-\mathrm{k}}\right)$ and microwave frequency $\left(\omega_{\mathrm{m}}\right)$ were disclosed for all nanoferrites. Coercivity $\left(\mathrm{H}_{\mathrm{c}}\right)$, squareness $(\mathrm{SQ})$, remanance $\left(\mathrm{M}_{\mathrm{r}}\right)$ and saturation magnetization $\left(\mathrm{M}_{\mathrm{s}}\right)$ all illustrated significant reducing trends with the addition of $\mathrm{Mg}^{2+}$ contents. Hence 
fabricated spinel ferrite materials are highly acceptable in microwave devices and in electrical transformers to remove eddy current losses.

Keywords: Spinel ferrites; SEM; Optical band gap; DC resistivity; VSM; High Microwave Frequency

\section{Introduction}

In the modern era spinel ferrites are investigated for wide range of applications in the fields of electronics, electrical, magnetic, optoelectronics and electrochemical sciences [1]. The broad functions of these spinel ferrite materials have convinced the researchers. Size, shape, purity and magnetic stability of the ultrafine powder consisting of ferrite nanomaterials depends upon the processing conditions and synthesis method [2-3]. These soft ferrites can be used in different applications like magneto optical recording media and pulse power by varying the different parameters like low temperature annealing, doping, sintering at high temperature [49]. Ferrites retain the properties like lower dielectric fatalities, higher resistivity, larger Curie temperature, abatement cost and high macerating magnetization. Such characteristics may be improved with the addition of rare earth metals. Researchers have examined effects on structures and magnetic outcomes by accumulation of Sm, Gd, La, Ce and Y [10-12]. For different electrical and microwave properties lanthanum doped spinel ferrites have gained attention of researchers [12]. Electrical and magnetic properties are transformed by adding such rare earth metals in soft ferrites materials. Insertion of rare earth element $\left(\mathrm{Re}=\mathrm{La}^{3+}\right)$ in spinel ferrites is potential candidate to bring modifications in electrical and structural behaviors of nanoferrites [11,13]. In zinc, cobalt and magnesium ferrites rare earth metals are inserted to develop characteristics of materials and to bring improvements in resistivity and permeability [1]. Substitution of magnesium with cobalt shows typical dielectric behavior and low dielectric losses [14]. Different synthesis techniques like spraypyrolsis [15], citrate gel [16], hydro 
thermal [17], sol-gel [18], microwave refluxing [19] and co-precipitation [20, 21] can be implemented to synthesize the nanoferrite particles. Co-precipitation method is one of the best techniques to prepare nanoparticles as compared to others because of its' simplicity and low economic cost [22]. In current research work, we are studying $\mathrm{Mg}-\mathrm{Co}$ nanoferrites $\mathrm{Zn}_{0.4} \mathrm{Co}_{0.6}$ ${ }_{x} \mathrm{Mg}_{\mathrm{x}} \mathrm{Fe}_{1.9} \mathrm{La}_{0.1} \mathrm{O}_{4}(\mathrm{X}=0.00,0.15,0.30,0.45,0.60)$ fabricated by co-precipitation technique. Structural, optical, electrical, vibrational, dielectric and magnetic properties of synthesized nanomaterials have been investigated.

\section{Experimental}

\subsection{Synthesis Process}

$\mathrm{Mg}^{2+}$ inserted $\mathrm{Zn}_{0.4} \mathrm{Co}_{0.6-\mathrm{x}} \mathrm{Fe}_{1.9} \mathrm{La}_{0.1} \mathrm{O}_{4}(\mathrm{X}=0.00,0.15,0.30,0.45,0.60)$ nanomaterials were synthesized by co-precipitation method. Desired weights of zinc, magnesium, cobalt, iron and lanthanum nitrates $\left(\mathrm{Zn}\left(\mathrm{NO}_{3}\right)_{2} .6 \mathrm{H}_{2} \mathrm{O}_{4}, \mathrm{Mg}\left(\mathrm{NO}_{3}\right)_{2} .6 \mathrm{H}_{2} \mathrm{O}_{4}, \mathrm{Co}\left(\mathrm{NO}_{3}\right)_{2} .6 \mathrm{H}_{2} \mathrm{O}_{4}, \mathrm{Fe}\left(\mathrm{NO}_{3}\right)_{3} .9 \mathrm{H}_{2} \mathrm{O}_{4}\right.$ and $\mathrm{La}\left(\mathrm{NO}_{3}\right)_{3} .6 \mathrm{H}_{2} \mathrm{O}_{4}$ ) were liquefied in de-ionized water distinctly according to the stochiometric ratios. The solutions were blended together with constant stirring at $60{ }^{\circ} \mathrm{C}$. To keep pH 12 sodium hydro-oxide solution was augmented as a precipitous factor. Formed solution was kept in $80{ }^{\circ} \mathrm{C}$ pre-heated water for 12 hours. In order to eradicate impurities of precipitates the solutions were washed severally with de-ionized water and ethanol. Obtained crystals were placed in oven at $80{ }^{\circ} \mathrm{C}$ to make water free. With the help of granite mortar pestle precipitates were crushed into powder. Powder was positioned in muffle furnace at $800{ }^{\circ} \mathrm{C}$ for 4 hours and 10 minutes. The specimens were again grinded until to accomplish fine powder. Schematic drawing of synthesis process is publicized in Fig. 1. 


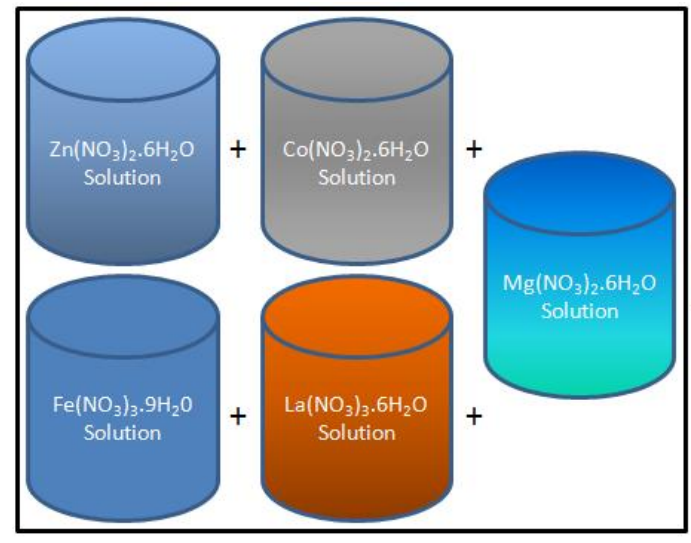

12g. $\mathrm{NaOH}+100 \mathrm{ml} . \mathrm{H}_{2} \mathrm{O}$ To keep pH 12
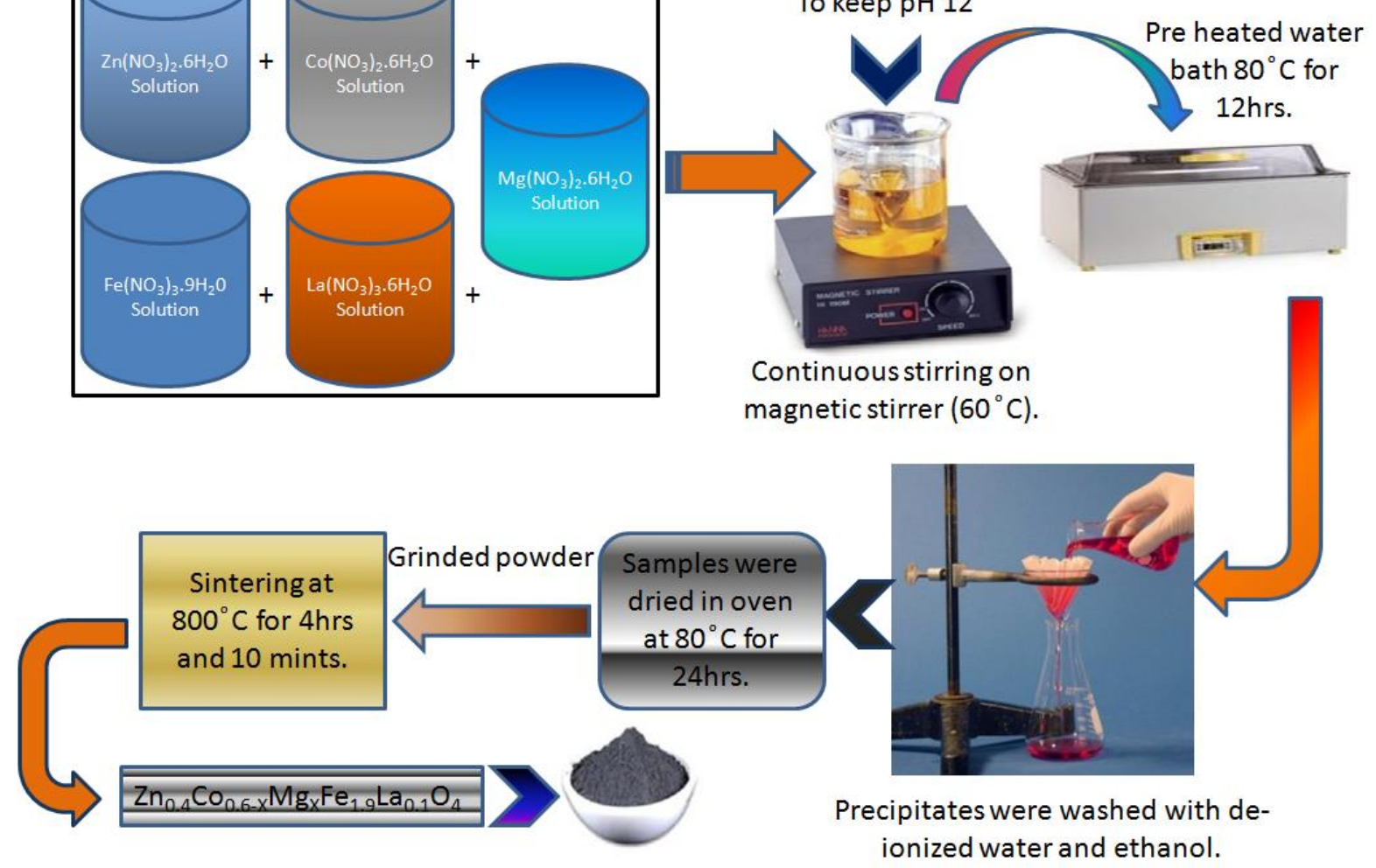

Fig. 1: Schematic diagram for synthesis of $\mathrm{Zn}_{0.4} \mathrm{Co0.6-x} \mathrm{Mg}_{\mathrm{x}} \mathrm{Fe}_{1.9 \mathrm{La}} \mathrm{LaO}_{4}(\mathrm{X}=0.00,0.15$, 0.30, $0.45,0.60)$ spinel ferrites.

\subsection{Characterization Techniques}

Numerous characterizations techniques are employed to study structural, morphological, optical, electrical, dielectric, vibrational and magnetic properties.

\section{Results and Discussion}

\subsection{Micro-structural Study}

Structure of $\mathrm{Zn}_{0.4} \mathrm{Co}_{0.6-\mathrm{x}} \mathrm{Mg}_{\mathrm{x}} \mathrm{Fe}_{1.9} \mathrm{La}_{0.1} \mathrm{O}_{4}(\mathrm{X}=0.00,0.15,0.30,0.45,0.60)$ spinel ferrites nanoparticles manufactured by co-precipitation scheme were configured by XRD. XRD patterns of $\mathrm{Mg}^{2+}$ doped nanoferrites are given in Fig. 2. Good crystallization and cubic structure were demonstrated by all materials. Most prominent peak lines (200), (220), (311), (400), (422) 
and (511) confirm the development of cubic spinel structure with single phase in all nanoferrites. This concluded that presented nanoferrites are consisted of spinel structure. Values of corporeal factors like crystalline size 'D', lattice constants 'a', inter planar spacing ' $\mathrm{d}$ ' and volume of unit cell ' $\mathrm{V}$ ' achieved commencing XRD data are given in Table 1. Replacement of cobalt with magnesium signifies that cobalt contents have been successfully entered spinel structure as disclosed by crystallite size and lattice constant. The heights of prominent peaks are increasing with decreasing contents of $\mathrm{Co}^{2+}$. This indicates that cobalt atoms are entirely incorporated into zinc magnesium ferrites. Same varieties of results were found by A. C. Druc et al. [14]. Also, as the $\mathrm{Mg}^{2+}$ contents increase the crystallite size decreases for $X=0.00$ to $X=0.45$. But when the cobalt content diminishes the crystallite size amplifies to maximum at $(\mathrm{X}=0.60)$. This is because of the relocation of $\mathrm{Fe}^{3+}$ ions as $\mathrm{Fe}^{3+}$ ions shifts from octahedral site to tetrahedral site to keep the charge neutral [23]. The lattice constant is observed in the range of $8.433-8.428$ for $\mathrm{X}=0.00-0.60$. Variations in lattice parameters are due to distinctions in ionic radii of both magnesium $\left(0.72 \mathrm{~A}^{\circ}\right)$ and cobalt $\left(0.74 \mathrm{~A}^{\circ}\right)$ [24]. Such variations in lattice constant were also discovered in $\mathrm{Mg}^{2+}$ doped $\mathrm{Co}_{0.6-\mathrm{x}} \mathrm{Zn}_{0.4} \mathrm{Fe}_{2} \mathrm{O}_{4}$ soft ferrites synthesized by co-precipitation technique observed by Manpreet Kaur et al., [25]. Additionally, the highest peak (311) is moving to the right with the enhancement of $\mathrm{Mg}^{2+}$ concentration as shown in the inset of Fig. 2. Table 1 also signifies that inter planar d-spacing and lattice constant are representing the same trends with the addition of magnesium contents. It means lattice parameter ' $\mathrm{a}$ ' is lessening slightly with the substitution of $\mathrm{Mg}^{2+}$ contents and magnesium has been successfully replaced with $\mathrm{Co}^{+2}$ ions. Such conduction is due to incorporation of lower ionic radius of $\mathrm{Mg}^{2+}$ than the $\mathrm{Co}^{2+}$. Calculated values of X-ray density $\left(\mathrm{d}_{\mathrm{x}}\right)$ measured from XRD analysis and Bulk density $\left(\mathrm{d}_{\mathrm{b}}\right)$ measured from nanoferrites pallets are illustrated in Table 1. $d_{x}$ is higher than $d_{b}$ because of the appearance of a few empty spaces during synthesis and annealing stage in nanocomposites [26-27]. Furthermore, $d_{x}$ is decreasing gradually because 
lattice constant is decreasing. Porosity ( $\mathrm{P} \%$ ) [28] is increasing steadily for $\mathrm{X}=0.00-0.60$ as clear from Table 1. H. M. Zaki et al. [29]. have explained the same kinds of porosity percentages. Also bulk density is decreasing because atomic weight of $\mathrm{Mg}^{2+}$ is lower than the $\mathrm{Co}^{2+}$ results the increase in porosity as clear from Table 1.

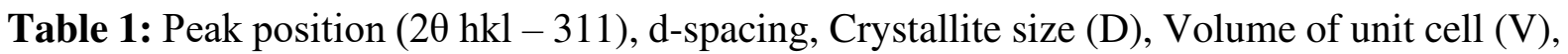
Experimental and theoretical lattice constant $\left(\mathrm{a}_{\exp }, \mathrm{a}_{\mathrm{th}}\right), \mathrm{X}$-ray and bulk density $\left(\mathrm{d}_{\mathrm{x}}, \mathrm{d}_{\mathrm{b}}\right)$ and Porosity ( $\mathrm{P} \%$ ) of $\mathrm{Zn}_{0.4} \mathrm{Co}_{0.6-\mathrm{x}} \mathrm{Mg}_{\mathrm{x}} \mathrm{Fe}_{1.9} \mathrm{La}_{0.1} \mathrm{O}_{4}(\mathrm{X}=0.00,0.15,0.30,0.45,0.60)$ compositions.

\begin{tabular}{lccccc}
\hline Parameters & $\mathbf{X = 0 . 0 0}$ & $\mathbf{X = 0 . 1 5}$ & $\mathbf{X = 0 . 3 0}$ & $\mathbf{X = 0 . 4 5}$ & $\mathbf{X = 0 . 6 0}$ \\
\hline 2 $\theta$ (hk1-311) (Degree) & 35.342 & 35.383 & 35.403 & 35.403 & 35.362 \\
d-spacing & 2.54279 & 2.53996 & 2.53859 & 2.53855 & 2.54137 \\
$\mathrm{D}(\mathrm{nm})$ & 22.91 & 18.16 & 18.11 & 17.39 & 29.11 \\
$\mathrm{~V}\left(A^{\circ}\right)^{3}$ & 599.80 & 597.81 & 596.83 & 596.81 & 598.80 \\
$\mathrm{a}_{\mathrm{exp}}\left(A^{\circ}\right)$ & 8.433 & 8.424 & 8.419 & 8.418 & 8.428 \\
$\mathrm{a}_{\mathrm{th}}\left(A^{\circ}\right)$ & 8.568 & 8.564 & 8.559 & 8.555 & 8.553 \\
$\mathrm{~d}_{\mathrm{x}}\left(\mathrm{g}-\mathrm{cm}^{-3}\right)$ & 5.44 & 5.35 & 5.24 & 5.12 & 5.00 \\
$\mathrm{~d}_{\mathrm{b}}\left(\mathrm{g}-\mathrm{cm}^{-3}\right)$ & 4.14 & 4.06 & 3.97 & 3.88 & 3.79 \\
$\mathrm{P}(\%)$ & 0.238 & 0.241 & 0.242 & 0.241 & 0.240 \\
\hline
\end{tabular}




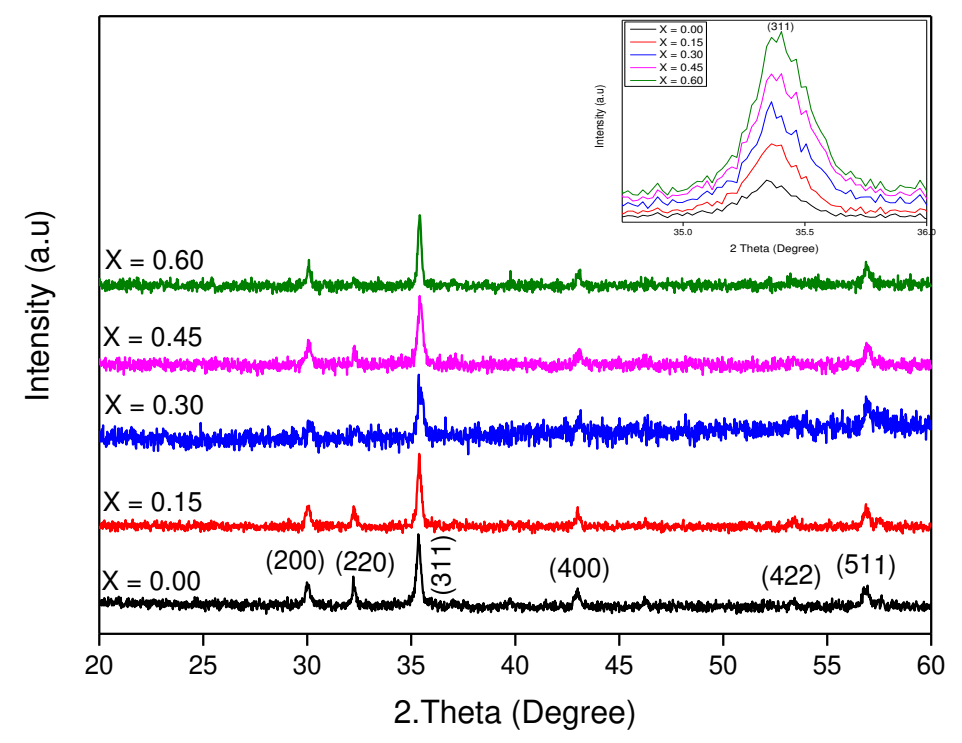

Fig. 2: $\mathrm{X}$-ray Diffractogram for $\mathrm{Zn}_{0.4} \mathrm{Co}_{0.6-\mathrm{x}} \mathrm{Mg}_{\mathrm{x}} \mathrm{Fe}_{1.9} \mathrm{La}_{0.1} \mathrm{O}_{4}(\mathrm{X}=0.00,0.15,0.30,0.45,0.60)$ soft ferrites

Theoretical lattice constant ath determine for samples are illustrated in Table 1. The experimental lattice constant $\mathrm{a}_{\exp }$ are slightly lower than theoretical lattice constant $\mathrm{a}_{\text {th }}$ and may be due to presence of $\mathrm{Fe}^{2+}$ ions. Because $\mathrm{Fe}^{2+}\left(0.67 A^{\circ}\right)$ ions have larger ionic radii as than the $\mathrm{Fe}^{3+}\left(0.64 A^{\circ}\right)$ ions. Also the slight difference in values of $\mathrm{a}_{\text {th }}$ may be due to an account of supposition of cations and anions normal arrangements in perfect unit cell structure obtained for theoretical computations [30].

\subsection{Scanning Electron Microscopy}

Obtained micro images from Scanning electron microscopy (SEM) of nanoferrites sintered at $800^{\circ} \mathrm{C}$ for all compositions are illustrated in Fig. $3(\mathrm{a}-\mathrm{e})$. From the micrographs it can be observed the formation of dispersed spherical nanoferrites particles. It can also be revealed that particles size is decreasing with amplify in concentration of $\mathrm{Mg}^{2+}$ contents for $\mathrm{X}$ 
$=0.00$ to $X=0.45$. While the particle size is detected higher for $X=0.60$ specimen. Hence, the majority of nanoparticles are in agglomerated contour and homogeneous allocation due to growth of magnesium doping. Grains expansion occurs as of grain boundary distribution. Activation energy for $\mathrm{Mg}^{2+}$ is lower (grain boundary diffusion) than cobalt (lattice diffusion) [31-32]. The illustrated outcomes are well supported with the XRD results. Also declination in sharpening of peaks with doping verified the decline in particle size [25].
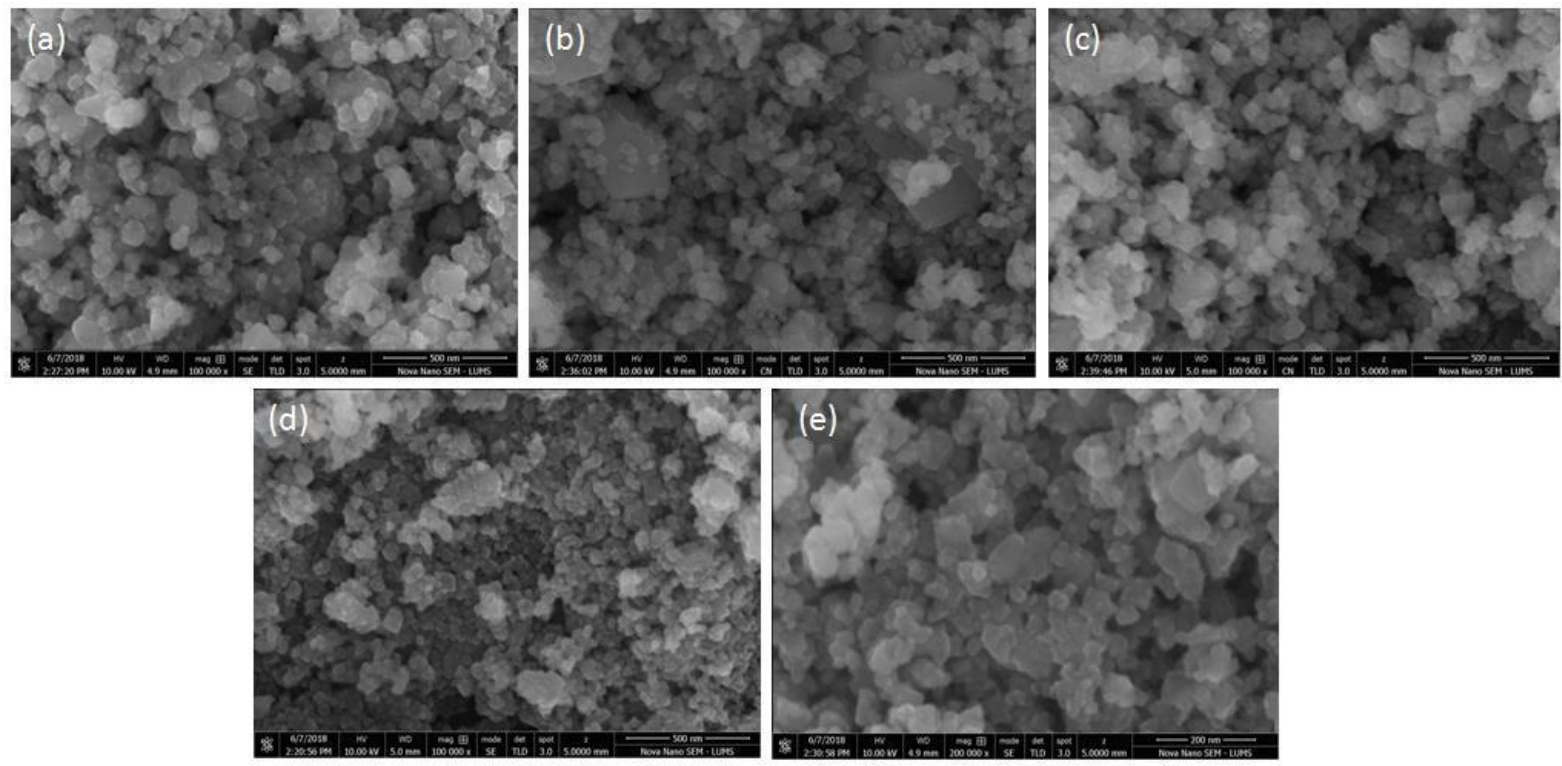

Fig. 3 (a - e): SEM images for $\mathrm{Zn}_{0.4} \mathrm{Co}_{0.6-\mathrm{x}} \mathrm{Mg}_{\mathrm{x}} \mathrm{Fe}_{1.9} \mathrm{La}_{0.1} \mathrm{O}_{4}$ soft ferrite $(\mathrm{X}=0.00,0.15,0.30$, $0.45,0.60)$.

\subsection{Ultraviolet Visible Spectroscopy Analysis}

Various methods are employed to study optical properties, UV-Vis is one of the accepted methods as compared to others. Synthesized intermingles of $\mathrm{Zn}_{0.4} \mathrm{Co}_{0.6-\mathrm{x}} \mathrm{Mg}_{\mathrm{x}} \mathrm{Fe}_{1.9} \mathrm{La}_{0.1} \mathrm{O}_{4}(\mathrm{X}=$ $0.00,0.15,0.30,0.45,0.60)$ spinel ferrites through de-ionized water was prepared. By plotting relation between $(\alpha \mathrm{h} v)^{2}$ and $(\mathrm{h} v)$ the optical band gap energy (Eg) is calculated for linear portion. $\mathrm{E}_{\mathrm{g}}$ for direct band gap is computed as of direct transition. UV-vis optical spectrum is plotted in Fig. 4 along with band gap. Absorption spectrum of the given ferrite samples lie in 
the visible region. With the boost of $\mathrm{Mg}^{2+}$ contents form $\mathrm{X}=0.0$ to 0.60 band gap energy $\left(\mathrm{E}_{\mathrm{g}}\right)$ decreases as was expected. $E_{\mathrm{g}}$ decreases from 2.65 to $1.85 \mathrm{eV}$ with the increasing concentration of $\mathrm{Mg}^{2+}$ or decreasing concentration of $\mathrm{Co}^{2+}$. These band gaps ranges are strongly agreed to the results demonstrated by A. Godlyn Abraham et al. [33]. The reduction in Eg value is because of reduction in contents of $\mathrm{Mg}^{2+}$ as $\mathrm{Mg}^{2+}$ is more conductive than $\mathrm{Co}^{2+}$. The decreasing distances amongst valance band and conduction band means that nanoferrites are showing stronger semiconducting nature. Optical band gap energies $\left(E_{g}\right)$ of soft nanoferrites are exposed in Table 3.

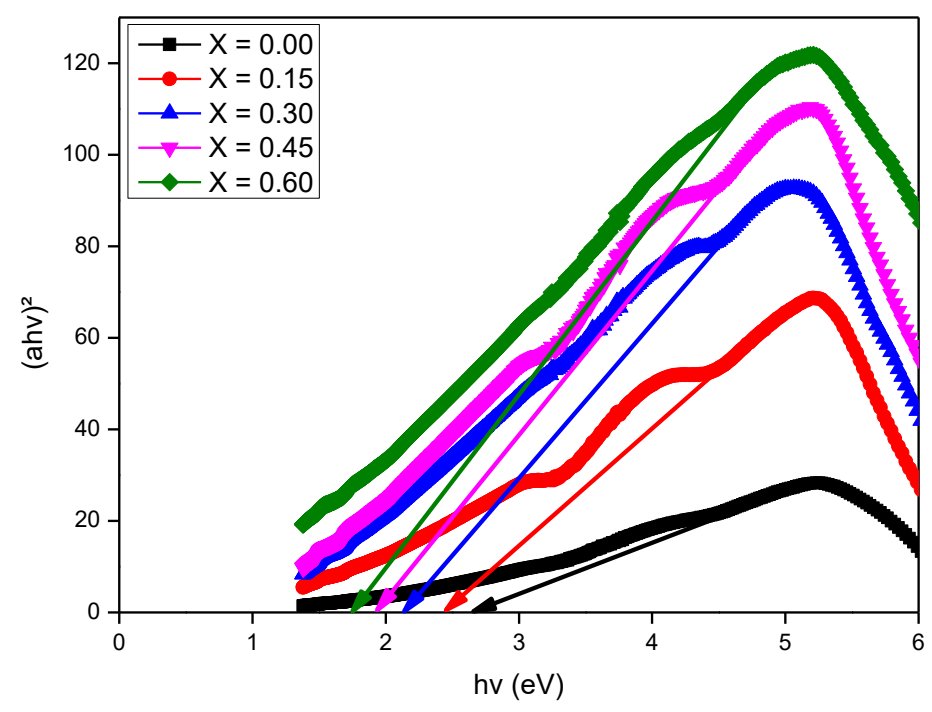

Fig. 4: Tauc's plot for optical band band gap measurements where the arrows lying on X-axis represent the exact value of optical band gap energy $(\mathrm{eV})$ for $\mathrm{Zn}_{0.4} \mathrm{Co}_{0.6-\mathrm{x}} \mathrm{Mg}_{\mathrm{x}} \mathrm{Fe}_{1.9} \mathrm{La}_{0.1} \mathrm{O}_{4}$ soft ferrite $(X=0.00,0.15,0.30,0.45,0.60)$

\subsection{Raman Spectroscopy}

Raman spectra of for $\mathrm{Zn}_{0.4} \mathrm{Co}_{0.6-\mathrm{X}} \mathrm{Mg}_{\mathrm{X}} \mathrm{Fe}_{1.9} \mathrm{La}_{0.1} \mathrm{O}_{4}(\mathrm{X}=0.00,0.15,0.30,0.45,0.60)$ is given in Fig. 5. To reveal vibrational and structural properties of soft nanoferrites Raman spectroscopy is useful tool. For normal spinel structure, group theory predicted five active phonon modes of 
Raman including $\left(\Gamma=1 \mathrm{~A}_{1 \mathrm{~g}}+1 \mathrm{E}_{\mathrm{g}}+3 \mathrm{~T}_{2 \mathrm{~g}}\right)$ [34]. Raman shift modes around $388.26 \mathrm{~cm}^{-1}$ was made by F. Nakagomi et al. [35]. H. S. Mund et al. have exposed above $600 \mathrm{~cm}^{-1}$ as high frequency Raman mode $\left(\mathrm{A}_{1 \mathrm{~g}}\right)$ disclosing local lattice consequence in tetrahedral sub-lattice [8]. Whereas, $\left(E_{g}\right.$ and $\left.T_{2 g}\right)$ are smaller frequency Raman modes corresponding to local lattice outcomes in octahedral sub-lattice sites. Various Raman modes for current $\mathrm{Mg}^{2+}$ inserted $\mathrm{Zn}$ Co-La soft ferrites nanomaterials are exemplified in table 2. 329, 470, 529, 638 and 682 are five peaks maxima corresponding to $\mathrm{E}_{\mathrm{g}}, \mathrm{T}_{2 \mathrm{~g}}(2), \mathrm{T}_{2 \mathrm{~g}}(3), \mathrm{A}_{1 \mathrm{~g}}(1)$ and $\mathrm{A}_{1 \mathrm{~g}}(2)$ for nanoferrites. No comments are existed concerning the region of Raman mode 388 in literature [35]. For cobalt ferrites these modes are well adjusted with reported literature [36]. Maximum position $692 \mathrm{~cm}^{-}$ ${ }^{1}$ is allotted to $\mathrm{Zn}_{0.4} \mathrm{Mg}_{0.6} \mathrm{Fe}_{1.9} \mathrm{La}_{0.1} \mathrm{O}_{4}$ type of ferrites and is strongly agreed with present situation [37]. In Raman spectroscopy due to distinctions in ionic radii of magnesium, cobalt and iron significant distributions are observed for band distances. Results obtained from bond distances distribution illustrate similar double peak arrangement related to $A_{1 g}$ and $E_{g}$. Magnesium has lower atomic mass than cobalt resulting the Raman band to shift higher frequency. Relation between positions of Raman active modes against $\mathrm{Mg}^{2+}$ concentration is given in Fig. 6.

Table 2: Raman phonon modes for $\mathrm{Zn}_{0.4} \mathrm{Co}_{0.6-\mathrm{X}} \mathrm{Mg}_{\mathrm{X}} \mathrm{Fe}_{1.9} \mathrm{La}_{0.1} \mathrm{O}_{4}(\mathrm{X}=0.00,0.15,0.30,0.45$, 0.60) nanoparticles

\begin{tabular}{cccccc}
\hline $\mathbf{X}$ & $\mathbf{E}_{\mathbf{g}}$ & $\mathbf{T}_{\mathbf{2 g}}(\mathbf{2})$ & $\mathbf{T}_{\mathbf{2 g}}(\mathbf{3})$ & $\mathbf{A}_{\mathbf{1 g}}(\mathbf{1})$ & $\mathbf{A} \mathbf{g}(\mathbf{2})$ \\
\hline 0.00 & 329 & 470 & 529 & 638 & 682 \\
0.15 & 314 & 466 & 529 & 618 & 669 \\
0.30 & 329 & 468 & 529 & 633 & 669 \\
0.45 & 314 & 470 & 529 & 629 & 676 \\
0.60 & 329 & 480 & 529 & 651 & 692 \\
\hline
\end{tabular}




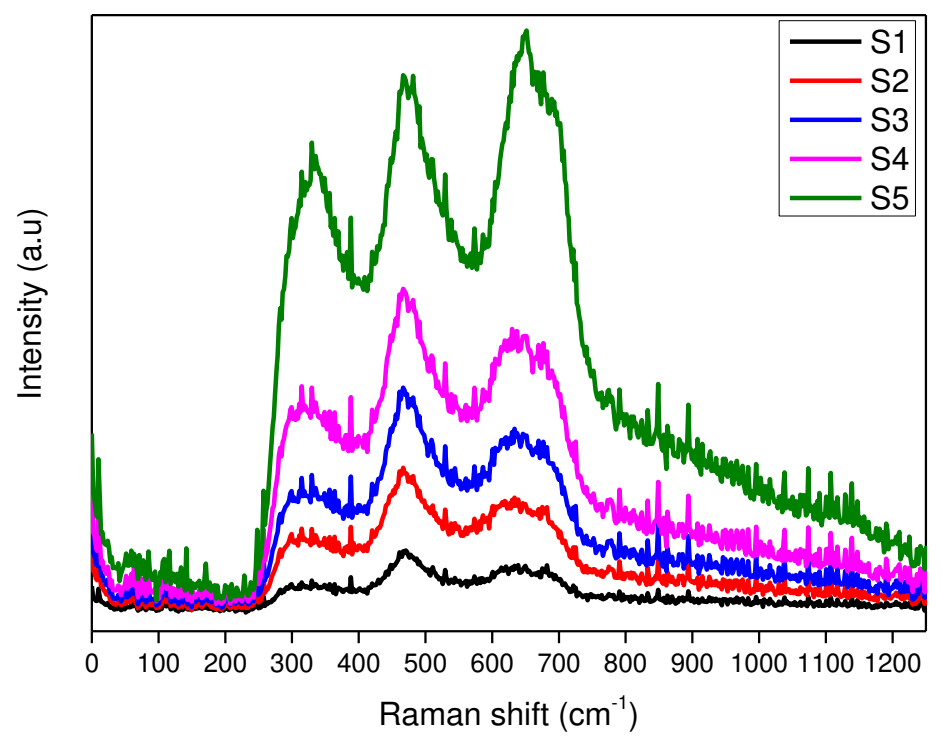

Fig. 5: Raman spectra of for $\mathrm{Zn}_{0.4} \mathrm{Co}_{0.6-\mathrm{X}} \mathrm{Mg}_{\mathrm{X}} \mathrm{Fe}_{1.9} \mathrm{La}_{0.1} \mathrm{O}_{4}(\mathrm{X}=0.00,0.15,0.30,0.45,0.60)$ soft nanoferrites

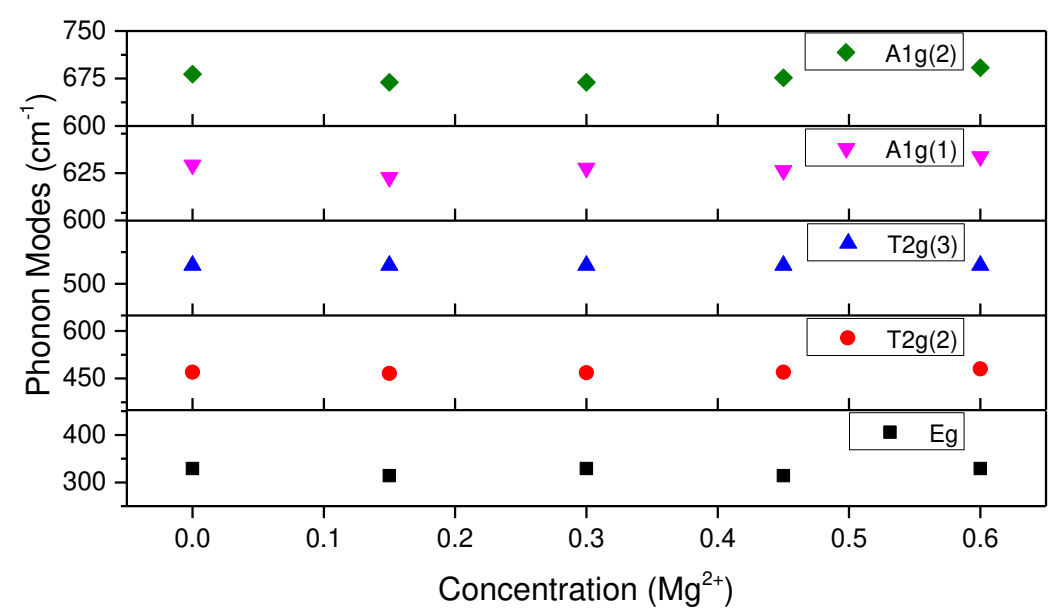

Fig. 6: Observed Raman modes $\left(\mathrm{cm}^{-1}\right)$ vs. concentration $\mathrm{Mg}^{2+}$ for $\mathrm{X}=0.00-0.60$

\subsection{Electrical Properties}

Two probes technique was applied by utilizing Keithley Electrometer Model 2401 for I-V characterization of nano-ferrites. Pallets of nano-ferrites were fabricated with particular dimensions. I-V curves in slope forms for all samples were measured between $323-873 \mathrm{~K}$ 
temperatures. Calculated Electrical resistivity resistivity $(\rho)$ for $X=0.00-0.60$ is in the range of $4.61 * 10^{9}-5.39 * 10^{6} \mathrm{ohm}-\mathrm{cm}$ as shown in Table 3 at $373 \mathrm{~K}$ temperature. Electrical resistivity is linked with arrangements of nanoferrite specimens and crystal configuration. Reducing in electrical resistivity with enhancement of magnesium contents is illustrated in Fig. 7. This reveals that with the augmentation of $\mathrm{Mg}^{2+}$ concentrations, resistivity decreases.

All nanoferrites specimens have shown semi-conducting nature. Trends of electrical resistivity depending on variations in temperatures are explained in Fig. 8. From Fig. 8 graph advocates that from 323 - $373 \mathrm{~K}$ temperature, log of resistivity increases and then start decreasing till to 873 K. In Fig. 8 curves are cracked into two regions knows as ferrimagnetic and paramagnetic [38]. The insertion of $\mathrm{Zn}-\mathrm{Mg}$-Co contents in fabricated ferrites boost quantity of divalent iron ions to enhance hopping between Fe iron ions and lead the reduction in DC resistivity. At 373 $\mathrm{K}$ temperature called transition temperature the kink appears. This indicates the transformations in magnetic arrangement commencing ferrimagnetism to paramagnetism during conductivity in soft ferrites. Segments positioned earlier than the transition temperature is ferrimagnetism whereas after this temperature is paramagnetism. Activation energies for ferrimagnetism $\left(E_{f}\right)$ and paramagnetism $\left(E_{p}\right)$ are illustrated in Table 3. Relation between activation energy $\left(\Delta \mathrm{E}=\mathrm{E}_{\mathrm{p}}-\mathrm{E}_{\mathrm{f}}\right)$ with increase in $\mathrm{Mg}^{2+}$ contents is illustrated in Fig. 9. Activation energy declines with the enhancement of $\mathrm{Mg}^{2+}$ contents and reduction of $\mathrm{Co}^{2+}$ contents for $\mathrm{X}=0.00-0.60$. The calculated values of activation energies for all nanoferrites signify that hopping of electrons was likely responsible mechanism of conduction in ferrites. Such decreasing activation energy behavior is well agreed with literature [39]. The hopping of electrons in same element with respective lattice sites leads the conduction procedure in ferrites [40]. M. R. Anantharaman et al, described that $\mathrm{DC}$ resistivity arises due to $\mathrm{Fe}^{2+}$ ions [41]. Also the resistivity range demonstrated by the samples of the materials are highly applicable for 
telecommunication $\left(10^{8} \Omega . \mathrm{cm}\right)$ and low resistive devices like transformers to control eddy current losses [38-43]

Table 3: Band gap energy $\left(E_{g}\right)$, Electrical resistivity $\left(\rho_{D C}\right)$, activation energy of paramagnetism $\left(E_{p}\right)$ and ferromagnetism $\left(E_{f}\right)$, change in activation energy $(\Delta E)$ and drift mobility $\left(\mu_{d}\right)$ for nanoferrite compositions.

\begin{tabular}{lccccc}
\hline Parameters & \multicolumn{5}{c}{ Results } \\
\hline $\mathrm{X}$ & 0.00 & 0.15 & 0.30 & 0.45 & 0.60 \\
\hline $\mathrm{Eg}(\mathrm{eV})$ & 2.65 & 2.50 & 2.15 & 1.95 & 1.85 \\
$\rho_{\mathrm{DC}}(\Omega . \mathrm{cm})$ at $373 \mathrm{~K}$ & $4.61 * 10^{9}$ & $9.44 * 10^{8}$ & $7.11^{*} 10^{8}$ & $1.13 * 10^{7}$ & $5.39 * 10^{6}$ \\
$\mathrm{E}_{\mathrm{p}}(\mathrm{eV})$ & -0.0008969 & -0.000956 & -0.000913 & -0.000884 & -0.00084 \\
$\mathrm{E}_{\mathrm{f}}(\mathrm{eV})$ & 0.0003706 & 0.0009270 & 0.0016150 & 0.001849 & 0.003568 \\
$\Delta \mathrm{E}=\mathrm{E}_{\mathrm{p}}-\mathrm{E}_{\mathrm{f}}(\mathrm{eV})$ & -0.0008969 & -0.001883 & -0.002528 & -0.002733 & -0.00441 \\
$\mu_{\mathrm{d}}\left(\mathrm{cm}^{2} \mathrm{~V}^{-1} \mathrm{~s}^{-1}\right)$ & $9.81 * 10^{-15}$ & $4.69 * 10^{-14}$ & $6.09 * 10^{-14}$ & $3.73 * 10^{-12}$ & $7.69 * 10^{-12}$ \\
\hline
\end{tabular}




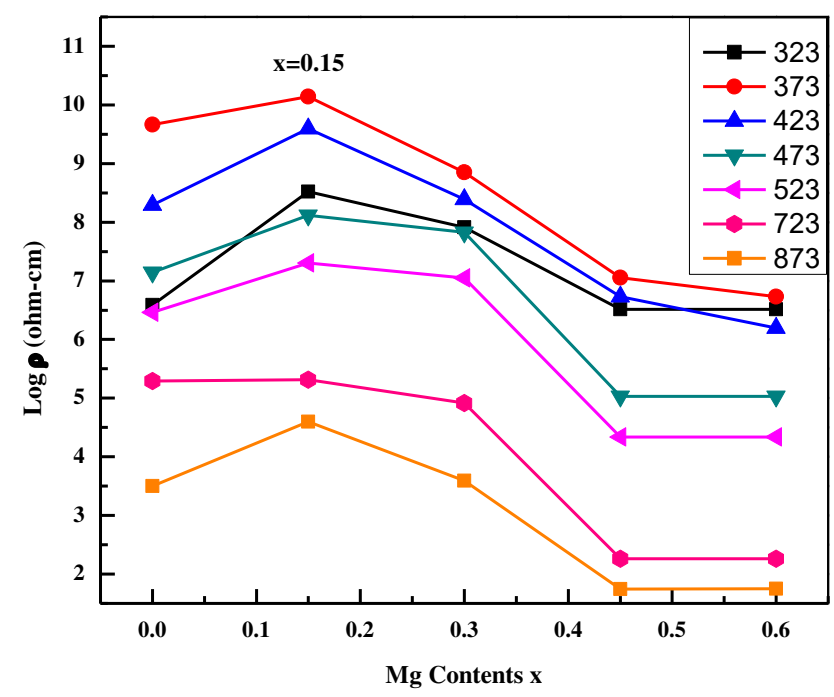

Fig. 7: $\mathrm{Log}$ resistivity $(\mathrm{ohm}-\mathrm{cm})$ versus $\mathrm{Mg}^{2+}$ contents

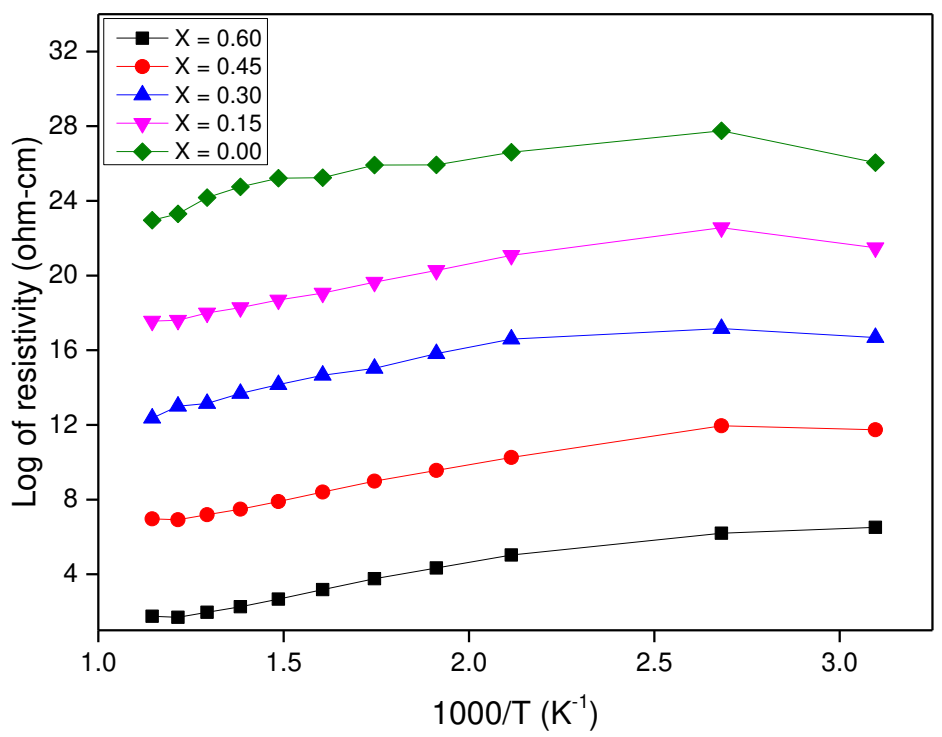

Fig. 9: Resistivity trend as a function of $1000 / \mathrm{T} \mathrm{Zn}_{0.4} \mathrm{Co}_{0.6-\mathrm{x}} \mathrm{Mg}_{\mathrm{x}} \mathrm{Fe}_{1.9} \mathrm{La}_{0.1} \mathrm{O}_{4}(\mathrm{X}=0.00,0.15$, $0.30,0.45,0.60)$. 


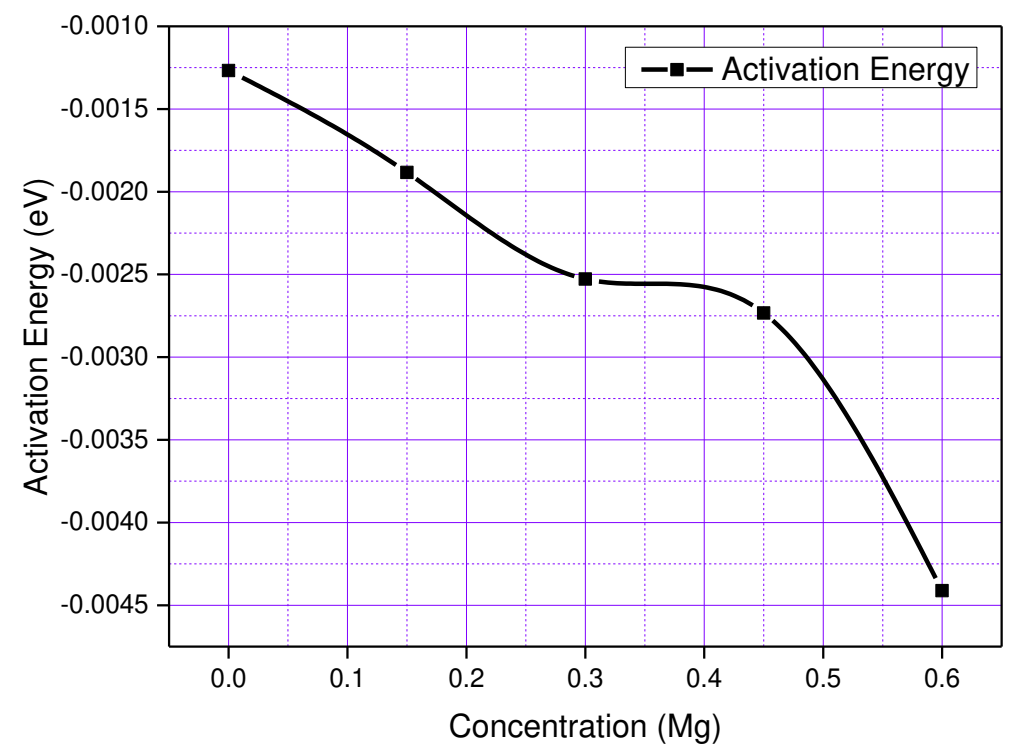

Fig. 9: Activation energy (eV) versus concentration of $\mathrm{Mg}^{2+}$ for $\mathrm{Zn}_{0.4} \mathrm{Co}_{0.6-\mathrm{X}} \mathrm{Mg}_{\mathrm{X}} \mathrm{Fe}_{1.9} \mathrm{La}_{0.1} \mathrm{O}_{4}$

$$
(\mathrm{X}=0.00,0.15,0.30,0.45,0.60)
$$

\subsubsection{Drift Mobility}

Fig. 10 demonstrates the relation connecting drift mobility $\left(\mu_{d}\right)$ and temperature for $\mathrm{X}=0.00$ - 0.60. $\mu_{d}$ shows escalating order with increase of temperature. Enhancement in temperature boosts enough energy to improve charge carriers hopping from one cationic site to other. It can be observed that $\mu_{d}$ is growing up with the raise of $\mathrm{Mg}^{2+}$ contents as illustrated in Table 3 . The points showing low drift mobility means temperature has not supplied sufficient potential to develop charge carriers to click from one site to another. Enrichment in $\mu_{d}$ with the boost of $\mathrm{Mg}^{2+}$ contents advocates the enhancement of hopping from one cationic site to other for all nanoferrites synthesized particles. DC resistivity and drift mobility have inverse relation with each others. 


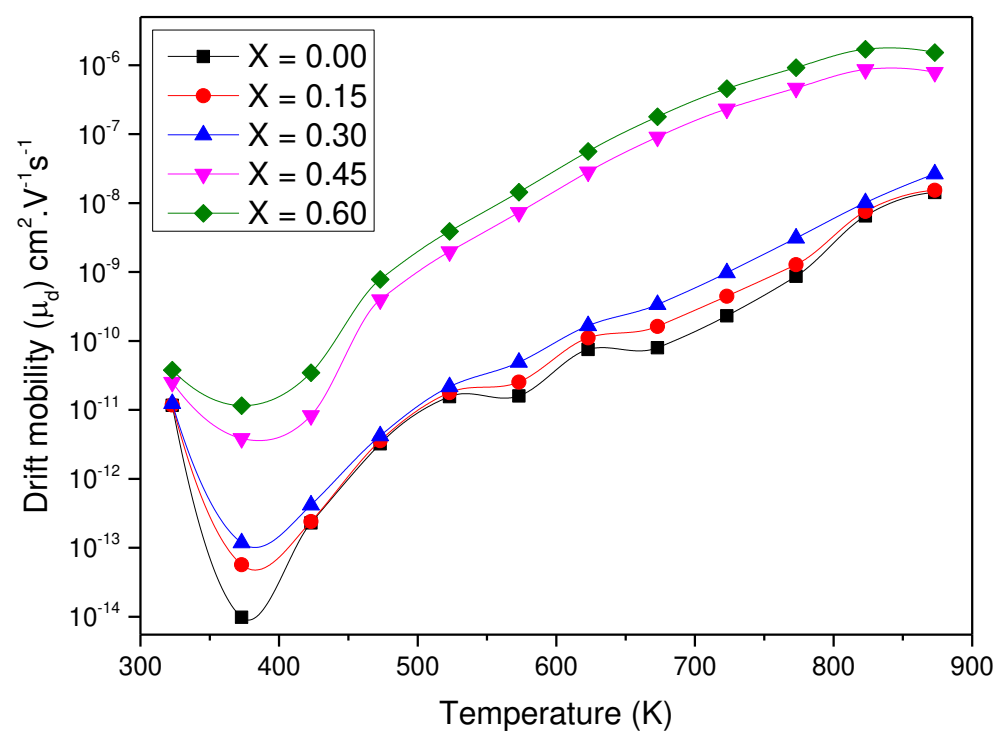

Fig. 10: Relation between temperature $(K)$ and drift mobility $\left(\mu_{D C}\right)$ for $X=0.00-0.60$ nanoferrites.

\subsection{Dielectric Properties}

Dielectric characteristics are interdependent on synthesis situations including annealing temperature, duration, nature and amount of essences [44]. Fig. 11 gives the plot of dielectric losses $(\tan \delta)$ and frequency. Dielectric loss demonstrates same trends like $\dot{\varepsilon}$ with rise of frequency. In small frequency region loss factor has greater values for nanoferrites because hopping frequency is larger than the applied frequency hence, loss is extreme as electrons track the field. Loss is least at higher frequency because electrons delay behind the field [45]. Fig. 12 stretches the relation amongst impedance ( $\mathrm{Z}$ ) and frequency. From the Fig. it can be observed that at low frequency for $\mathrm{X}=0.00$ impedance is higher and starts decline for the rest of the specimens with the increase of $\mathrm{Mg}^{2+}$ contents. Results also perceived that as frequency enhances impedance of all nanoferrites attribute stable trends. 


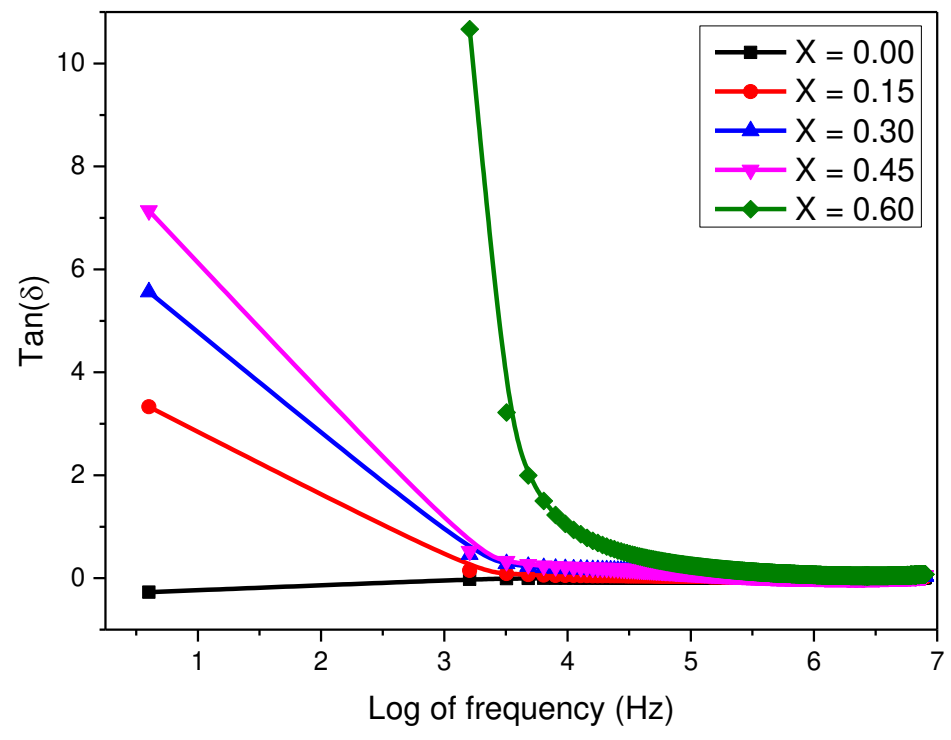

Fig. 11: Dielectric loss (tan $\delta)$ of $\mathrm{Zn}_{0.4} \mathrm{Co}_{0.6-\mathrm{X}} \mathrm{Mg}_{\mathrm{X}} \mathrm{Fe}_{1.9} \mathrm{La}_{0.1} \mathrm{O}_{4}(\mathrm{X}=0.00,0.15,0.30,0.45$, 0.60) spinel ferrite

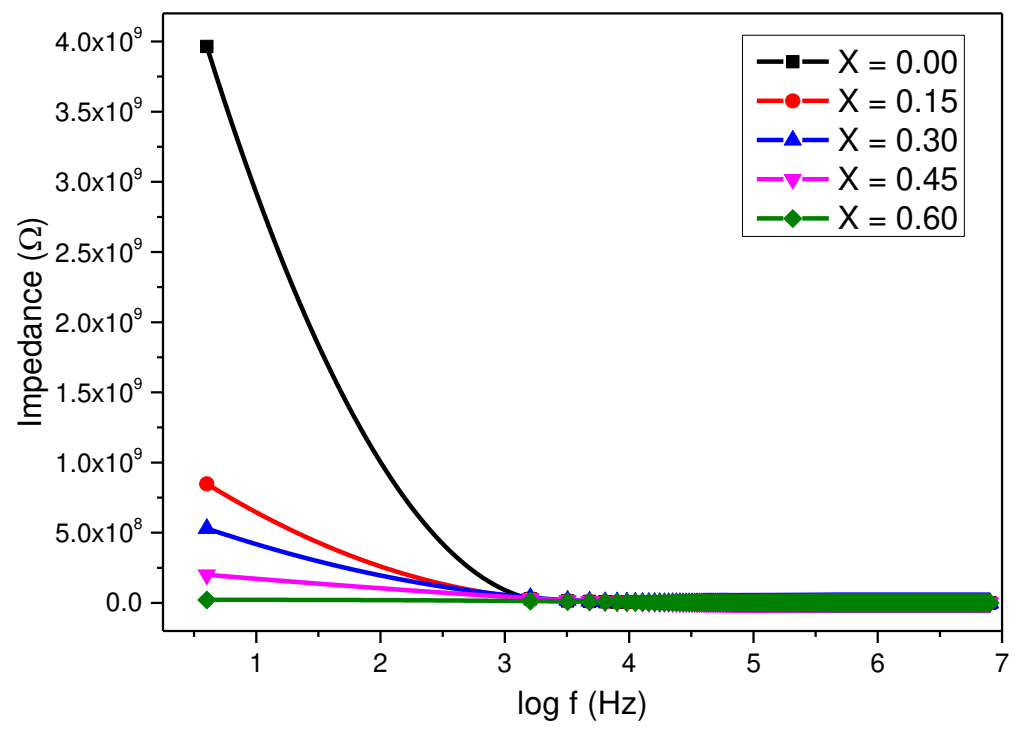

Fig. 12: Impedance vs. log of frequency of $\mathrm{Zn}_{0.4} \mathrm{Co}_{0.6-\mathrm{X}} \mathrm{Mg}_{\mathrm{XFe}}{ }_{1 .} \mathrm{La}_{0.1} \mathrm{O}_{4}(\mathrm{X}=0.00,0.15,0.30$, $0.45,0.60)$ spinel ferrite 
Vibrating Sample Magnetometer called VSM was employed to examine magnetic performances of $\mathrm{Mg}^{2+}$ doped $\mathrm{Zn}$-Co-La nanoferrites. 1.5 $\mathrm{T}$ maximum field was applied at room temperature as exposed in M-H loop of Fig. 13 for all composed soft ferrites. Effect of stochiometric variations disclosed by VSM outcomes on remnant magnetization $\left(\mathrm{M}_{\mathrm{r}}\right)$, coercivity $\left(\mathrm{H}_{\mathrm{c}}\right)$, remnant squareness $(\mathrm{SQ})$ and saturation magnetization $\left(\mathrm{M}_{\mathrm{S}}\right)$, considerations depending on density, anisotropy, crystallite development and A - B sharing interaction factors for fabricated ferrites. Table 4 demonstrates the computed parameters for $\mathrm{Zn}_{0.4} \mathrm{Co}_{0.6-}$ ${ }_{x} \mathrm{Mg}_{\mathrm{X}} \mathrm{Fe}_{1.9} \mathrm{La}_{0.1} \mathrm{O}_{4}$ where $\mathrm{X}=0.00,0.15,0.30,0.45,0.60$ nanoferrites. Fig. 13 illustrates the change in magnetic behavior of $\mathrm{Zn}_{0.4} \mathrm{Co}_{0.6-\mathrm{x}} \mathrm{Mg}_{\mathrm{x}} \mathrm{Fe}_{1.9} \mathrm{La}_{0.1} \mathrm{O}_{4}$ with the increase in $\mathrm{Mg}^{2+}$ contents and corresponding decrease in $\mathrm{Co}^{2+}$. Outcomes easily reveal that as $\mathrm{Mg}^{2+}$ contents augment there is clear decrease in magnetization and in the overall magnetic behavior of the material. As a matter of fact $\mathrm{Co}^{2+}$ is ferromagnetic in nature whereas $\mathrm{Mg}^{2+}$ is paramagnetic and this is clear evidence that with the more number of cobalt contents the material is supposed to manifest unlike having more number of paramagnetic counter parts. The experimental outcomes for $\mathrm{M}_{\mathrm{s}}$ is $60.82 \mathrm{emu} / \mathrm{g}$ for $\mathrm{X}=0.00$ and this decreased to a minimum value of 25.94 $\mathrm{emu} / \mathrm{g}$ for $\mathrm{X}=0.60$. 


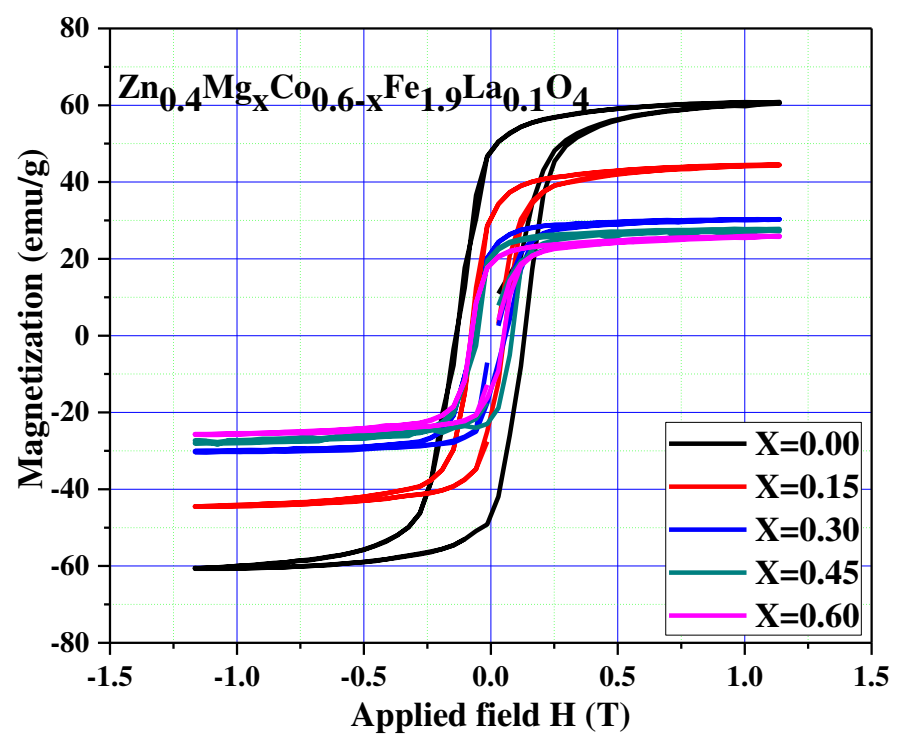

Fig. 13: Concentrational dependence of magnetization in $\mathrm{Zn}_{0.4} \mathrm{Co}_{0.6-\mathrm{x}} \mathrm{Mg}_{\mathrm{x}} \mathrm{Fe}_{1.9} \mathrm{La}_{0.1} \mathrm{O}_{4}(\mathrm{X}=$ $0.00,0.15,0.30,0.45,0.60)$ spinel ferrite

Fig. 14 shows the change in coercivity and remnant squareness or remnant ratio $\left(S Q=M_{r} / M_{s}\right)$ with the increase in $\mathrm{Mg}$ contents. A gradual decrease can be observed in both magnetic parameters owing to the substitution of Co atoms. Moreover one of the possible reasons for this trend could the formation of antiferromagnetic regions inside the compound which again results in the loss of free ferromagnetic Co atoms. This formation possibly cause the reduction in saturation magnetization and that affects the coercivity and squareness values from maximum values $\mathrm{H}_{\mathrm{c}}=1334 \mathrm{Oe}, \mathrm{SQ}=0.78$ to minimum values $\mathrm{H}_{\mathrm{c}}=511 \mathrm{Oe}, \mathrm{SQ}=0.51$. 


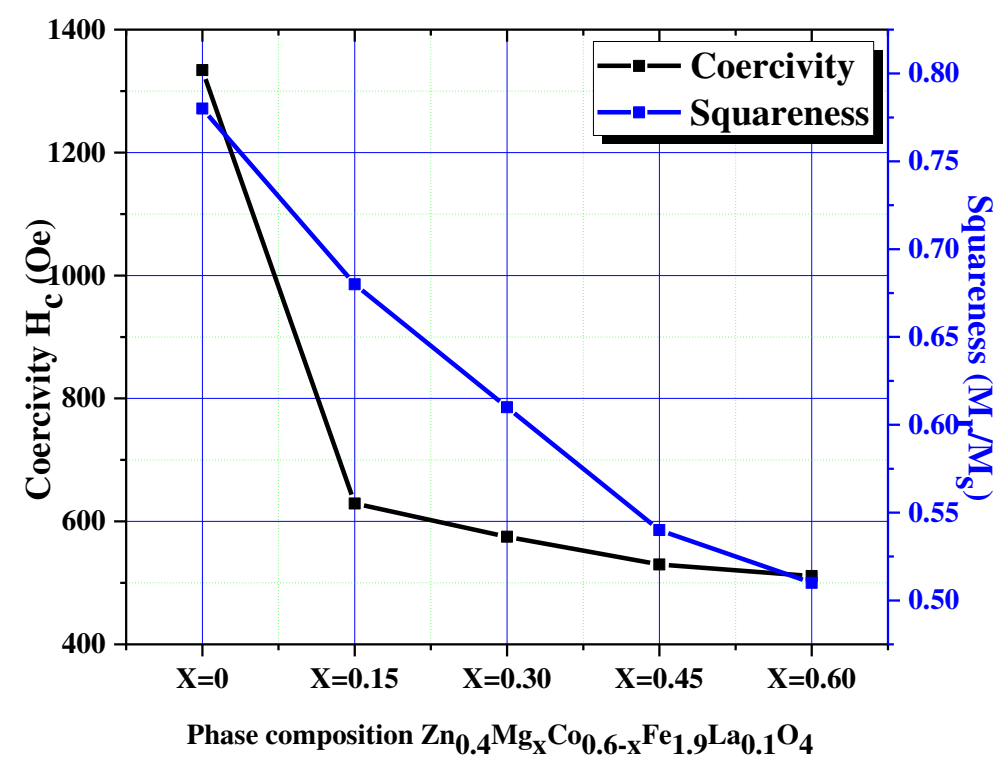

Fig. 14: Variation in coercivity (Hc) and remnant squareness (SQ) with the decrease in Co contents in $\mathrm{Zn}_{0.4} \mathrm{Co}_{0.6-\mathrm{X}} \mathrm{Mg}_{\mathrm{X}} \mathrm{Fe}_{1.9} \mathrm{La}_{0.1} \mathrm{O}_{4}(\mathrm{X}=0.00,0.15,0.30,0.45,0.60)$ spinel ferrite

Various other magnetic parameters were calculated including Bohr's magneton $\left(\mu_{B}\right)$, Magnetocrystalline anisotropy constant (K), Yafet and Kittel $(\mathrm{Y}-\mathrm{K})$ for the synthesized nanoferrites. Magnetic moment $\mathrm{n}_{\mathrm{B}}$ and anisotropy constant $\mathrm{K}$ are revealing reducing trends as in Table 4. Difference in magnetic moment of $\mathrm{Mg}^{2+}\left(0 \mu_{\mathrm{B}}\right)$ and $\mathrm{Co}^{2+}\left(3.88 \mu_{\mathrm{B}}\right)$ is caused in lessening $n_{B}$ and $K$ [46]. Super exchange interactions are feeble in magnetic parameters of $\mathrm{Mg}^{2+}$ inserted ferrites. Ferromagnetic orders dissimilarity commencing collinear to non collinear or triangle spin are bases in declining of these factors [47]. Magnetic characteristics are mainly attracted by ionic radius of doped materials and rest of cations in spinel ferrites. Hence bond lengths and ionic radii are responsible for magnetic performance of nanoparticles. Cations existed in nanoferrites have $\mathrm{Zn}^{2+}\left(0 \mu_{\mathrm{B}}\right), \mathrm{Mg}^{2+}\left(0 \mu_{\mathrm{B}}\right), \mathrm{Co}^{2+}\left(3.88 \mu_{\mathrm{B}}\right), \mathrm{La}^{3+}\left(0 \mu_{\mathrm{B}}\right)$ and $\mathrm{Fe}^{3+}\left(5 \mu_{\mathrm{B}}\right)$ magnetic moments [9]. Individually $\mathrm{Co}^{2+}$ has higher magnetic moment than $\mathrm{Zn}^{2+}$ and $\mathrm{Mg}^{2+}$, so replacement of $\mathrm{Mg}^{2+}$ ions have capability to share large number of $\mathrm{Fe}^{3+}$ ions at particular site. This manner leads the discrepancy in initial permeability as in Table 4. It can 
be observed that initially $\mu_{\mathrm{i}}$ increases for $\mathrm{X}=0.00$ and 0.15 and then starts decreases quickly and gains maximum value for $X=0.60$. The growing trend shown by the $\mu_{\mathrm{i}}$ is due to the increasing concentration of non-magnetic ions. The decreasing nature is because of reducing in bulk density as in Table 1 by constructing the domain wall moments and domain rotation inside the ferrites to become hard. Electric and magnetic losses severely affect operational abilities of devices. So operational frequency for nanoferrites made gadgets are directly associated to microwave frequency. Following relation can be employed to study microwave frequency $\left(\omega_{\mathrm{m}}\right)$ as $[48-49]$,

$$
\omega_{\mathrm{m}}=8 \pi^{2} M_{s} \gamma
$$

Where, $\gamma$ denotes gyromagnetic ratio having value $2.8 \mathrm{MHz} / \mathrm{Oe}$ and $\mathrm{M}_{\mathrm{s}}$ illustrates saturation magnetization. $13.4-5.7 \mathrm{G} . \mathrm{Hz}$ is computed $\left(\omega_{\mathrm{m}}\right)$ assortment for fabricated nanomaterials as depicted in Fig. 15 . Achieved range is well agreed with $\left(\omega_{\mathrm{m}}\right)$ bands range standard. Thus, $\mathrm{Mg}^{2+}$ and $\mathrm{La}^{3+}$ co-inserted $\mathrm{Zn}$-Co ferrites are excellent aspirants in high microwave frequency band purposes.

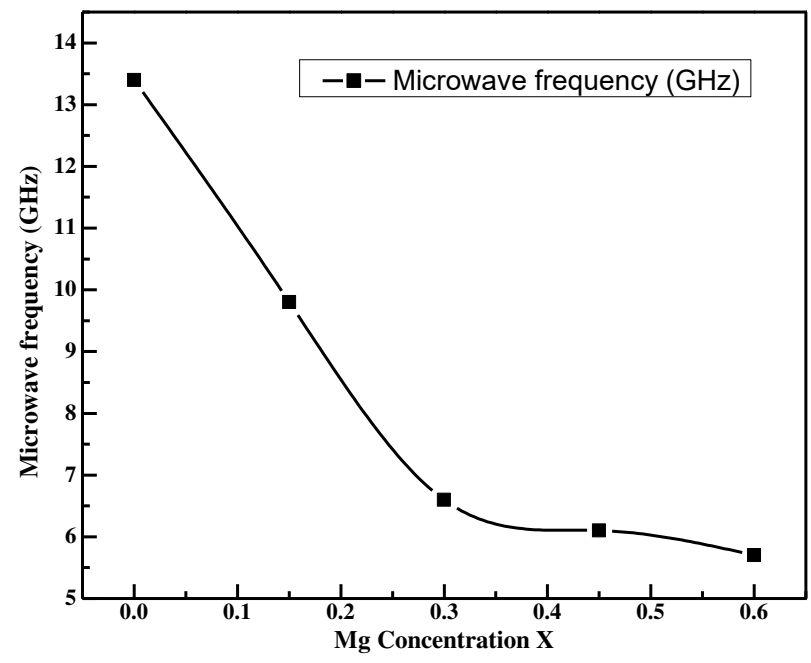


Fig. 15: Variation in microwave frequency with the decrease in Co contents in $\mathrm{Zn}_{0.4} \mathrm{Co}_{0.6}$ ${ }_{x} \mathrm{Mg}_{x} \mathrm{Fe}_{1.9} \mathrm{La}_{0.1} \mathrm{O}_{4}(\mathrm{X}=0.00,0.15,0.30,0.45,0.60)$ spinel ferrite

Table 4: Coercivity $\left(\mathrm{H}_{\mathrm{C}}\right)$, Remnant Squareness (SQ), Remanance $\left(\mathrm{M}_{\mathrm{r}}\right)$, Saturation Magnetization $\left(\mathrm{M}_{\mathrm{s}}\right)$, Magnetic moment $\left(\mu_{\mathrm{B}}\right)$, Anisotropy constant $(\mathrm{K})$, Initial permeability $\left(\mu_{\mathrm{i}}\right)$, Y-K angle $\left(\alpha_{\mathrm{y}-\mathrm{k}}\right)$ and Microwave frequency $\left(\omega_{\mathrm{m}}\right)$ for $\mathrm{Mg}^{2+}$ substituted soft ferrites

\begin{tabular}{|c|c|c|c|c|c|c|c|c|c|}
\hline$X$ & $\begin{array}{l}\mathrm{H}_{\mathrm{C}} \\
(\mathrm{Oe})\end{array}$ & SQ & $\begin{array}{c}\mathrm{M}_{\mathrm{r}} \\
(\mathrm{emu} / \mathrm{g})\end{array}$ & $\begin{array}{c}\mathrm{M}_{\mathrm{s}} \\
(\mathrm{emu} / \mathrm{g})\end{array}$ & $\begin{array}{c}\mu_{\mathrm{B}} \\
(\mu \mathrm{B})\end{array}$ & $\begin{array}{c}\mathrm{K} \\
\left(\mathrm{erg} / \mathrm{cm}^{3}\right. \\
)\end{array}$ & $\mu_{\mathrm{i}}$ & $\begin{array}{c}\alpha_{\mathrm{y}-\mathrm{k}} \\
(\text { Deg. } \\
)\end{array}$ & $\begin{array}{c}\omega_{\mathrm{m}} \\
(\mathrm{G} . \mathrm{Hz} \\
\quad)\end{array}$ \\
\hline 0.00 & 1334 & 0.78 & 47.82 & 60.82 & 0.491 & 84514.45 & $\begin{array}{c}1.002 \\
7\end{array}$ & 23.79 & 13.4 \\
\hline 0.15 & 629 & 0.68 & 30.34 & 44.51 & 0.356 & 29163.32 & $\begin{array}{c}1.233 \\
6\end{array}$ & 41.47 & 9.8 \\
\hline 0.30 & 575 & 0.61 & 21.59 & 30.31 & 0.243 & 18154.42 & $\begin{array}{c}0.916 \\
4\end{array}$ & 53.54 & 6.6 \\
\hline 0.45 & 530 & 0.54 & 20.56 & 27.78 & 0.223 & 15336.87 & $\begin{array}{c}0.875 \\
0\end{array}$ & 64.54 & 6.1 \\
\hline 0.60 & 511 & 0.51 & 18.64 & 25.94 & 0.208 & 13807.64 & $\begin{array}{c}1.418 \\
6\end{array}$ & 70.44 & 5.7 \\
\hline
\end{tabular}

\section{Conclusion}

Co-precipitation technique was applied to fabricate magnesium doped $\mathrm{Zn}_{0.4} \mathrm{Co}_{0.6}$ ${ }_{x} \mathrm{Mg}_{\mathrm{x}} \mathrm{Fe}_{1.9} \mathrm{La}_{0.1} \mathrm{O}_{4}(\mathrm{X}=0.00,0.15,0.30,0.45,0.60$ soft ferrites. Cubic spinel structures of synthesized nanoferrites were confirmed by XRD pattern. Crystallite size and lattice constant 
showed declining trend for $\mathrm{X}=0.00-0.45$ and utmost value for $\mathrm{X}-0.60$. Cation $\operatorname{radii} \mathrm{r}_{\mathrm{A}}$ and $\mathrm{r}_{\mathrm{B}}$ demonstrated increasing and decreasing trends respectively with the incorporation of $\mathrm{Mg}^{2+}$ contents. Considerable decline in optical band gap energy $(2.65-1.85 \mathrm{eV})$ was noticed with amplification of magnesium contents. DC electrical resistivity diminished in the range of 4.61 $\mathrm{x} 10^{9}$ to $5.39 \times 10^{6} \Omega$-cm at $373 \mathrm{~K}$ Curie temperature. Activation energy decreased due to shrink in ionic distances. Drift mobility expressed enhancing trend with the increase in temperature. Five active phonon modes were detected like $\left(\Gamma=1 \mathrm{~A}_{1 \mathrm{~g}}+1 \mathrm{E}_{\mathrm{g}}+3 \mathrm{~T}_{2 \mathrm{~g}}\right)$ to disclose lattice consequences. Dielectric losses and impedance demonstrated diminishing trends with the enrichment of $\mathrm{Mg}^{2+}$ contents. magnetic parameters Coercivity $\left(\mathrm{H}_{\mathrm{c}}\right)$, squareness (SQ), remanance $\left(\mathrm{M}_{\mathrm{r}}\right)$ and saturation magnetization $\left(\mathrm{M}_{\mathrm{S}}\right)$ were decreased with the addition of $\mathrm{Mg}^{2+}$ contents. Magnetic nature of $\mathrm{Mg}^{2+}$ inserted $\mathrm{Zn}-\mathrm{Co}-\mathrm{La}$ nanferrites was lessening because of decrease in saturation magnetization of remanence values. Hence fabricated materials are highly acceptable in high microwave frequency devices. 


\section{References}

[1] C. Ramesh, K. Maniysundar, S. Selvanandan, Structural and magnetic study on Mg0. 3Zn0. 7NixFe2-xO4 ferrite system synthesized by sol-gel method, Materials Today: Proceedings 3 (2016) 1569-1575.

[2] M. Hashim, S. Meena, R. Kotnala, S.E. Shirsath, P. Bhatt, S. Kumar, E. Şentürk, R. Kumar,

N. Gupta, Exploring the structural, Mössbauer and dielectric properties of $\mathrm{Co} 2+$ incorporated Mg0. 5Zn0. 5- xCoxFe2O4 nanocrystalline ferrite, Journal of Magnetism and Magnetic Materials 360 (2014) 21-33.

[3] B.B.V.S. Vara Prasad, K.V. Ramesh, A. Srinivas, Physical, structural, morphological, magnetic and electrical properties of $\mathrm{Co} 0.5-\mathrm{xNixZn0.5Fe} 2 \mathrm{O} 4$ nanocrystalline ferrites, Ceramics International 45 (2019) 4549-4563.

[4] Y. Yang, M. Li, Y. Wu, T. Wang, E.S.G. Choo, J. Ding, B. Zong, Z. Yang, J. Xue, Nanoscaled self-alignment of Fe $3 \mathrm{O} 4$ nanodiscs in ultrathin rGO films with engineered conductivity for electromagnetic interference shielding, Nanoscale 8 (2016) 15989-15998.

[5] N. Thomas, P. Jithin, V. Sudheesh, V. Sebastian, Magnetic and dielectric properties of magnesium substituted cobalt ferrite samples synthesized via one step calcination free solution combustion method, Ceramics International 43 (2017) 7305-7310.

[6] L. Sun, R. Zhang, Q. Ni, E. Cao, W. Hao, Y. Zhang, L. Ju, Magnetic and dielectric properties of $\mathrm{MgxCo} 1-\mathrm{xFe} 2 \mathrm{O} 4$ ferrites prepared by the sol-gel method, Physica B: Condensed Matter 545 (2018) 4-11.

[7] J. Sharma, N. Sharma, J. Parashar, V. Saxena, D. Bhatnagar, K. Sharma, Dielectric properties of nanocrystalline Co-Mg ferrites, Journal of Alloys and Compounds 649 (2015) $362-367$. 
[8] H. Mund, B. Ahuja, Structural and magnetic properties of Mg doped cobalt ferrite nano particles prepared by sol-gel method, Materials Research Bulletin 85 (2017) 228-233.

[9] S. Bhukal, R. Sharma, S. Mor, S. Singhal, Mg-Co-Zn magnetic nanoferrites: characterization and their use for remediation of textile wastewater, Superlattices and Microstructures 77 (2015) 134-151.

[10] X. Zhong, X. Guo, S. Zou, H. Yu, Z. Liu, Y. Zhang, K. Wang, Improving soft magnetic properties of Mn-Zn ferrite by rare earth ions doping, AIP Advances 8 (2018) 047807.

[11] J. Jacob, M.A. Khadar, VSM and Mössbauer study of nanostructured hematite, Journal of Magnetism and Magnetic Materials 322 (2010) 614-621.

[12] J. Zhu, K. Tseng, Reducing dielectric losses in MnZn ferrites by adding TiO/sub 2/and MoO/sub 3, IEEE transactions on magnetics 40 (2004) 3339-3345.

[13] B.V. Prasad, K. Ramesh, A. Srinivas, Physical, structural, morphological, magnetic and electrical properties of $\mathrm{Co} 0$. 5-xNixZn0. 5Fe2O4 nanocrystalline ferrites, Ceramics International 45 (2019) 4549-4563.

[14] A. Druc, A. Borhan, A. Diaconu, A. Iordan, G. Nedelcu, L. Leontie, M. Palamaru, How cobalt ions substitution changes the structure and dielectric properties of magnesium ferrite?, Ceramics International 40 (2014) 13573-13578.

[15] K. Ukoba, A. Eloka-Eboka, F. Inambao, Review of nanostructured NiO thin film deposition using the spray pyrolysis technique, Renewable and Sustainable Energy Reviews 82 (2018) 2900-2915.

[16] P. Hankare, U. Sankpal, R. Patil, I. Mulla, P. Lokhande, N. Gajbhiye, Synthesis and characterization of $\mathrm{CoCrxFe} 2-\mathrm{xO} 4$ nanoparticles, Journal of Alloys and Compounds 485 (2009) 798-801. 
[17] S. Giri, S. Samanta, S. Maji, S. Ganguli, A. Bhaumik, Magnetic properties of $\alpha$-Fe2O3 nanoparticle synthesized by a new hydrothermal method, Journal of Magnetism and Magnetic Materials 285 (2005) 296-302.

[18] M. George, A.M. John, S.S. Nair, P. Joy, M. Anantharaman, Finite size effects on the structural and magnetic properties of sol-gel synthesized NiFe2O4 powders, Journal of Magnetism and Magnetic Materials 302 (2006) 190-195.

[19] P. Singjai, K. Wongwigkarn, Y. Laosiritaworn, R. Yimnirun, S. Maensiri, Carbon encapsulated nickel nanoparticles synthesized by a modified alcohol catalytic chemical vapor deposition method, Current Applied Physics 7 (2007) 662-666.

[20] R. Krishnakanth, G. Jayakumar, A.A. Irudayaraj, A.D. Raj, Structural and magnetic properties of $\mathrm{NiO}$ and $\mathrm{Fe}$-doped $\mathrm{NiO}$ nanoparticles synthesized by chemical Co-precipitation method, Materials Today: Proceedings 3 (2016) 1370-1377.

[21] T.M. Hammad, J.K. Salem, A.A. Amsha, N.K. Hejazy, Optical and magnetic characterizations of zinc substituted copper ferrite synthesized by a co-precipitation chemical method, Journal of Alloys and Compounds 741 (2018) 123-130.

[21] X. Gao, Y. Du, X. Liu, P. Xu, X. Han, Synthesis and characterization of Co-Sn substituted barium ferrite particles by a reverse microemulsion technique, Materials Research Bulletin 46 (2011) 643-648.

[23] M.A. Rafiq, M.A. Khan, M. Asghar, S. Ilyas, I. Shakir, M. Shahid, M.F. Warsi, Influence of $\mathrm{Co} 2+$ on structural and electromagnetic properties of $\mathrm{Mg}-\mathrm{Zn}$ nanocrystals synthesized via co-precipitation route, Ceramics International 41 (2015) 10501-10505.

[24] R. Sharma, P. Thakur, P. Sharma, V. Sharma, Ferrimagnetic Ni2+ doped Mg-Zn spinel ferrite nanoparticles for high density information storage, Journal of Alloys and Compounds 704 (2017) 7-17. 
[25] M. Kaur, P. Jain, M. Singh, Studies on structural and magnetic properties of ternary cobalt magnesium zinc (CMZ) Co0. 6-xMgxZn0. 4 Fe2O4 ( $\mathrm{x}=0.0,0.2,0.4,0.6)$ ferrite nanoparticles, Materials Chemistry and Physics 162 (2015) 332-339.

[26] M. Nahar, M.D. Rahaman, M. Khan, A. Hossain, Transport Behavior and Low Field Magnetoresistance of Polycrystalline La0. 63Y0. 07Sr0. 30MnO3 and La0. 63Y0. 07Ba0. 30MnO3, (2012).

[27] M.J. Iqbal, Z. Ahmad, Y. Melikhov, I.C. Nlebedim, Effect of $\mathrm{Cu}-\mathrm{Cr}$ co-substitution on magnetic properties of nanocrystalline magnesium ferrite, Journal of Magnetism and Magnetic Materials 324 (2012) 1088-1094.

[28] T. Shinde, A. Gadkari, P. Vasambekar, DC resistivity of Ni-Zn ferrites prepared by oxalate precipitation method, Materials Chemistry and Physics 111 (2008) 87-91.

[29] H. Zaki, S. Al-Heniti, T. Elmosalami, Structural, magnetic and dielectric studies of copper substituted nano-crystalline spinel magnesium zinc ferrite, Journal of Alloys and Compounds 633 (2015) 104-114.

[30] R. Sharma, S. Singhal, Structural, magnetic and electrical properties of zinc doped nickel ferrite and their application in photo catalytic degradation of methylene blue, Physica B: Condensed Matter 414 (2013) 83-90.

[31] S. Verma, J. Chand, M. Singh, Structural and electrical properties of A13+ ions doped nanocrystalline $\mathrm{Mg} 0.2 \mathrm{Mn} 0.5 \mathrm{Ni} 0.3 \mathrm{AlyFe} 2-\mathrm{yO} 4$ ferrites synthesized by citrate precursor method, Journal of Alloys and Compounds 587 (2014) 763-770.

[32] N. Singh, A. Agarwal, S. Sanghi, P. Singh, Effect of magnesium substitution on dielectric and magnetic properties of Ni-Zn ferrite, Physica B: Condensed Matter 406 (2011) 687-692. [33] A.G. Abraham, A. Manikandan, E. Manikandan, S. Vadivel, S. Jaganathan, A. Baykal, P.S. Renganathan, Enhanced magneto-optical and photo-catalytic properties of transition metal 
cobalt (Co2+ ions) doped spinel $\mathrm{MgFe} 2 \mathrm{O} 4$ ferrite nanocomposites, Journal of Magnetism and Magnetic Materials 452 (2018) 380-388.

[34] R. Gupta, A. Sood, P. Metcalf, J. Honig, Raman study of stoichiometric and Zn-doped Fe 3 O 4, Physical Review B 65 (2002) 104430.

[35] F. Nakagomi, S. Da Silva, V. Garg, A. Oliveira, P. Morais, A. Franco Jr, Influence of the Mg-content on the cation distribution in cubic MgxFe3- xO4 nanoparticles, Journal of Solid State Chemistry 182 (2009) 2423-2429.

[36] P. Chandramohan, M. Srinivasan, S. Velmurugan, S. Narasimhan, Cation distribution and particle size effect on Raman spectrum of CoFe2O4, Journal of Solid State Chemistry 184 (2011) 89-96.

[37] J. Chandradass, A.H. Jadhav, K.H. Kim, H. Kim, Influence of processing methodology on the structural and magnetic behavior of $\mathrm{MgFe} 2 \mathrm{O} 4$ nanopowders, Journal of Alloys and Compounds 517 (2012) 164-169.

[38] M. Raghasudha, D. Ravinder, P. Veerasomaiah, Electrical resistivity studies of Cr doped Mg nano-ferrites, Materials Discovery 2 (2015) 50-54.

[39] V. Vinayak, P.P. Khirade, S.D. Birajdar, R. Alange, K. Jadhav, Electrical and dielectrical properties of low-temperature-synthesized nanocrystalline $\mathrm{Mg} 2+$-substituted cobalt spinel ferrite, Journal of Superconductivity and Novel Magnetism 28 (2015) 3351-3356.

[40] E. Verwey, F. De Boer, J. Van Santen, Cation arrangement in spinels, The Journal of Chemical Physics 16 (1948) 1091-1092.

[41] M. Anantharaman, S. Jagatheesan, K. Malini, S. Sindhu, A. Narayanasamy, C. Chinnasamy, J. Jacobs, S. Reijne, K. Seshan, R. Smits, On the magnetic properties of ultrafine zinc ferrites, Journal of magnetism and magnetic materials 189 (1998) 83-88. 
[42] M. Mallapur, P. Shaikh, R. Kambale, H. Jamadar, P. Mahamuni, B. Chougule, Structural and electrical properties of nanocrystalline cobalt substituted nickel zinc ferrite, Journal of alloys and compounds 479 (2009) 797-802.

[43] R. Kambale, P. Shaikh, S. Kamble, Y. Kolekar, Effect of cobalt substitution on structural, magnetic and electric properties of nickel ferrite, Journal of Alloys and Compounds 478 (2009) 599-603.

[44] C. Sujatha, K.V. Reddy, K.S. Babu, A.R. Reddy, M.B. Suresh, K. Rao, Effect of Mg substitution on electromagnetic properties of $\mathrm{NiCuZn}$ ferrite, Journal of Magnetism and Magnetic Materials 340 (2013) 38-45.

[45] E. Melagiriyappa, H. Jayanna, B. Chougule, Dielectric behavior and ac electrical conductivity study of Sm3+ substituted $\mathrm{Mg}-\mathrm{Zn}$ ferrites, Materials chemistry and physics 112 (2008) 68-73.

[46] A.K. Singh, T. Goel, R. Mendiratta, Effect of manganese impurity on the conductivity, dielectric behavior and magnetic properties of Ni0. 3MnxZn0. 7-xFe2O4, Japanese journal of applied physics 42 (2003) 2690.

[47] F. ur Raheem, M.A. Khan, A. Majeed, A. Hussain, M.F. Warsi, M.N. Akhtar, Structural, spectral, electrical, dielectric and magnetic properties of $\mathrm{Yb}$ doped SrNiCo-X hexagonal nanostructured ferrites, Journal of Alloys and Compounds 708 (2017) 903-910.

[48] M.N. Akhtar, M. Saleem, M.A. Khan, Al doped spinel and garnet nanostructured ferrites for microwave frequency $\mathrm{C}$ and $\mathrm{X}$-band applications, Journal of Physics and Chemistry of Solids 123 (2018) 260-265.

[49] M.N. Akhtar, M. Babar, S. Qamar, Z. ur Rehman, M.A. Khan, Structural Rietveld refinement and magnetic features of prosademium (Pr) doped $\mathrm{Cu}$ nanocrystalline spinel ferrites, Ceramics International 45 (2019) 10187-10195. 


\section{Figures}
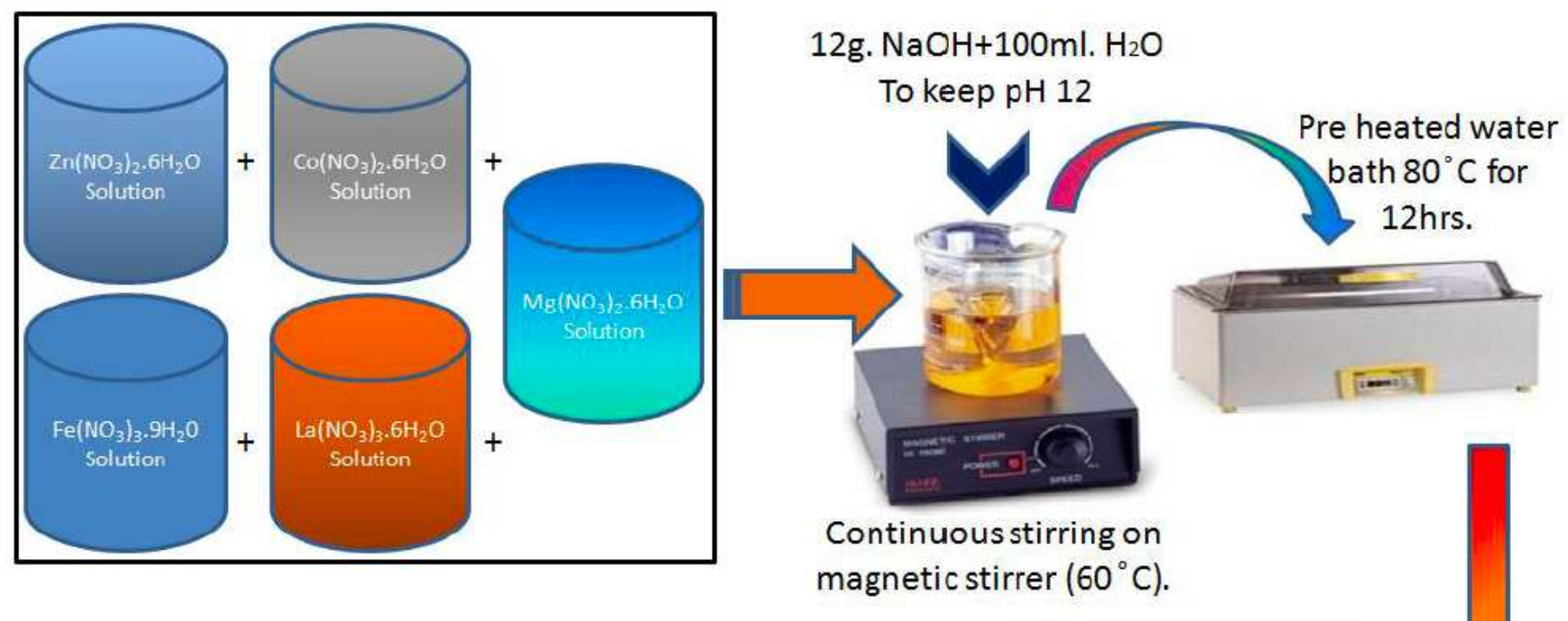

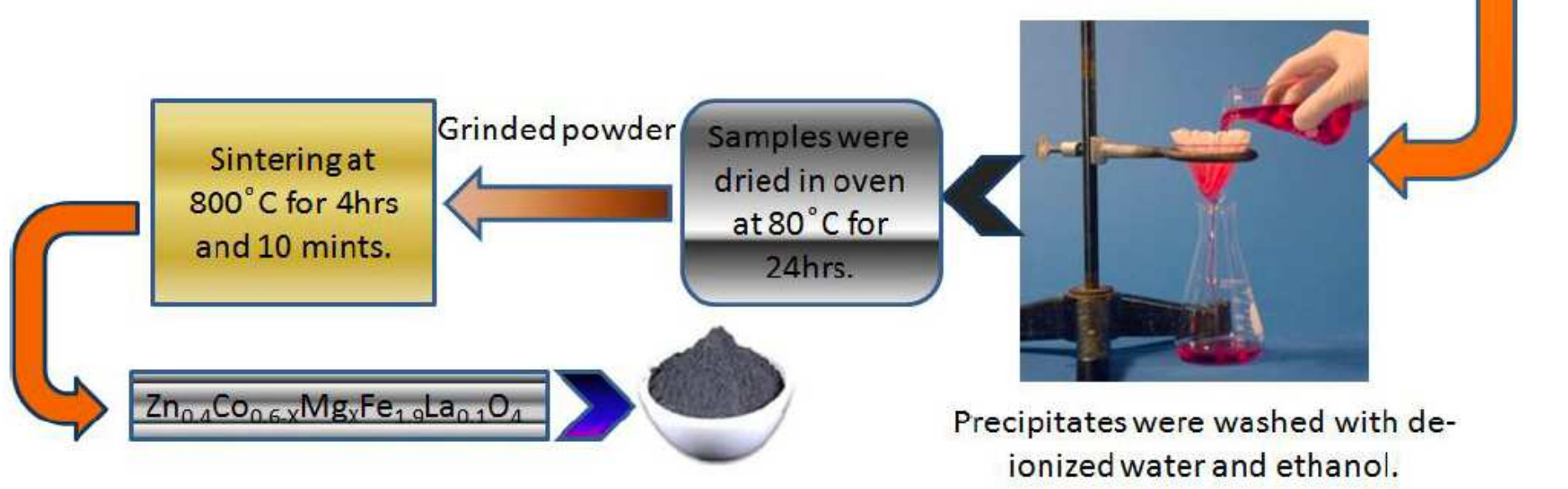

Figure 1

Schematic diagram for synthesis of Zn0.4Co0.6-xMgxFe1.9La0.104 (X = 0.00, 0.15, 0.30, 0.45, 0.60) spinel ferrites. 


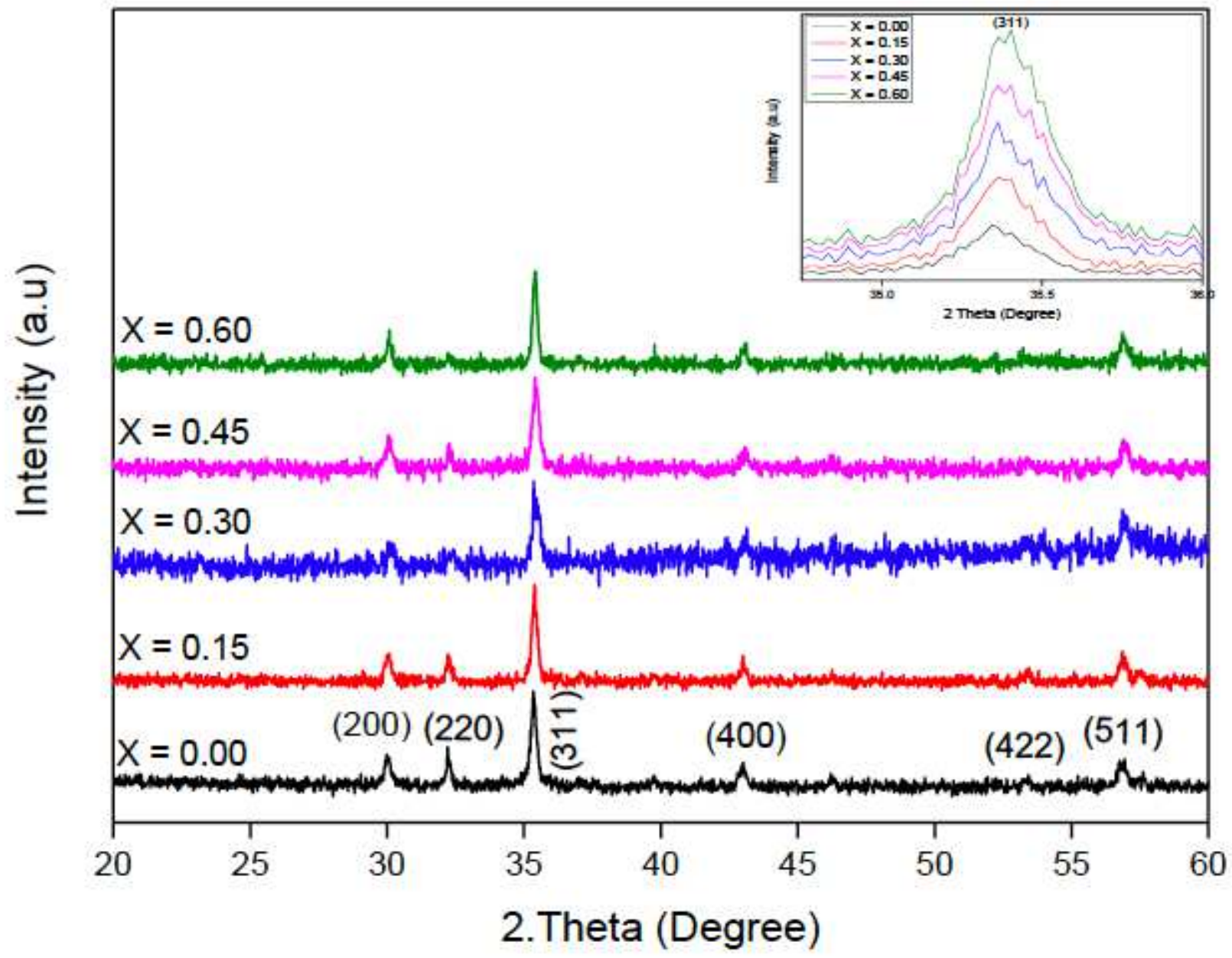

Figure 2

X-ray Diffractogram for Zn0.4Co0.6-xMgxFe1.9La0.104 ( $X=0.00,0.15,0.30,0.45,0.60)$ soft ferrites 

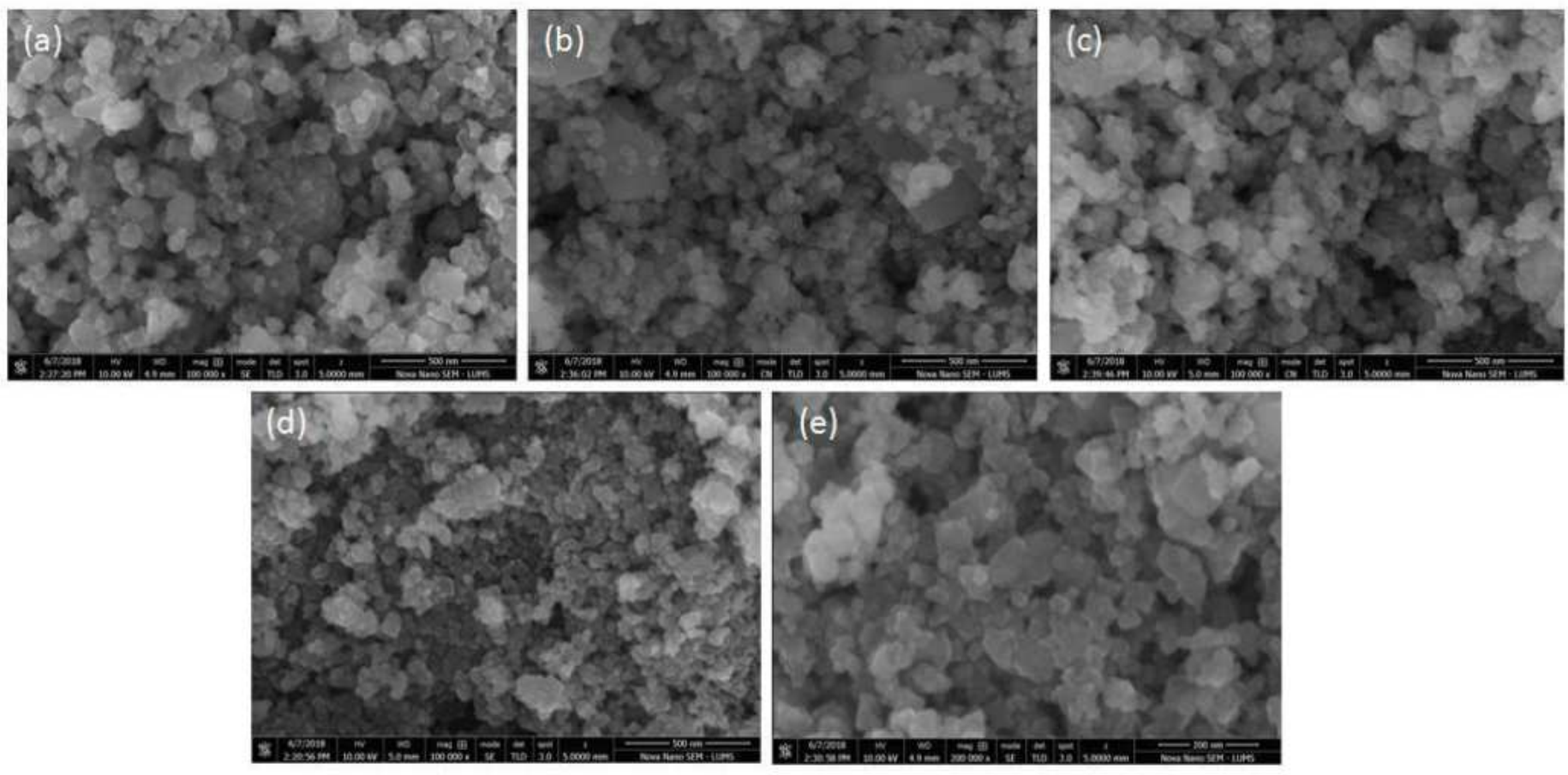

\section{Figure 3}

$(a-e)$ : SEM images for Zn0.4Co0.6-xMgxFe1.9La0.104 soft ferrite $(X=0.00,0.15,0.30,0.45,0.60)$. 


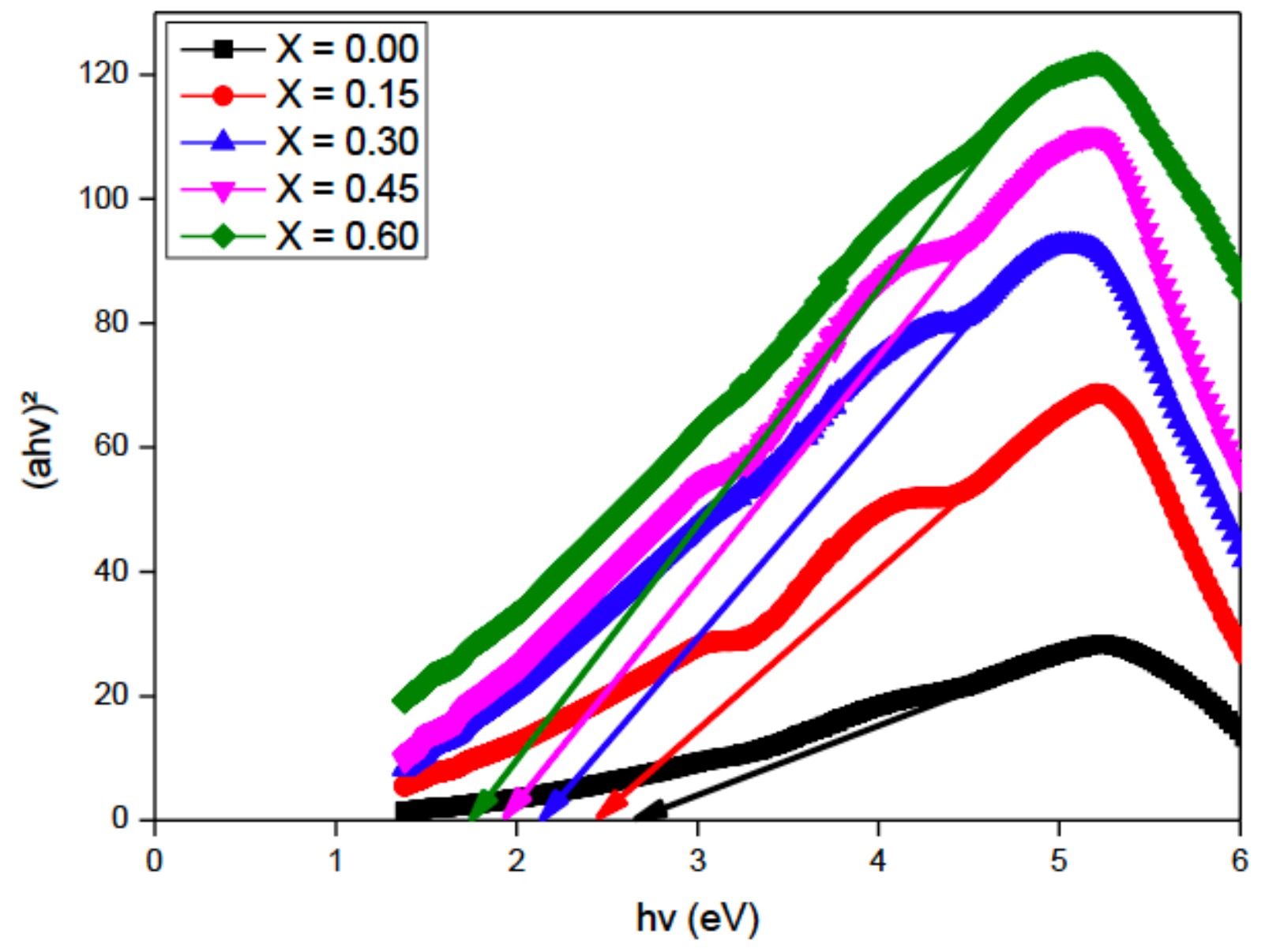

Figure 4

Tauc's plot for optical band band gap measurements where the arrows lying on X-axis represent the exact value of optical band gap energy (eV) for Zn0.4Co0.6-xMgxFe1.9La0.104 soft ferrite $(X=0.00,0.15,0.30$, $0.45,0.60)$ 


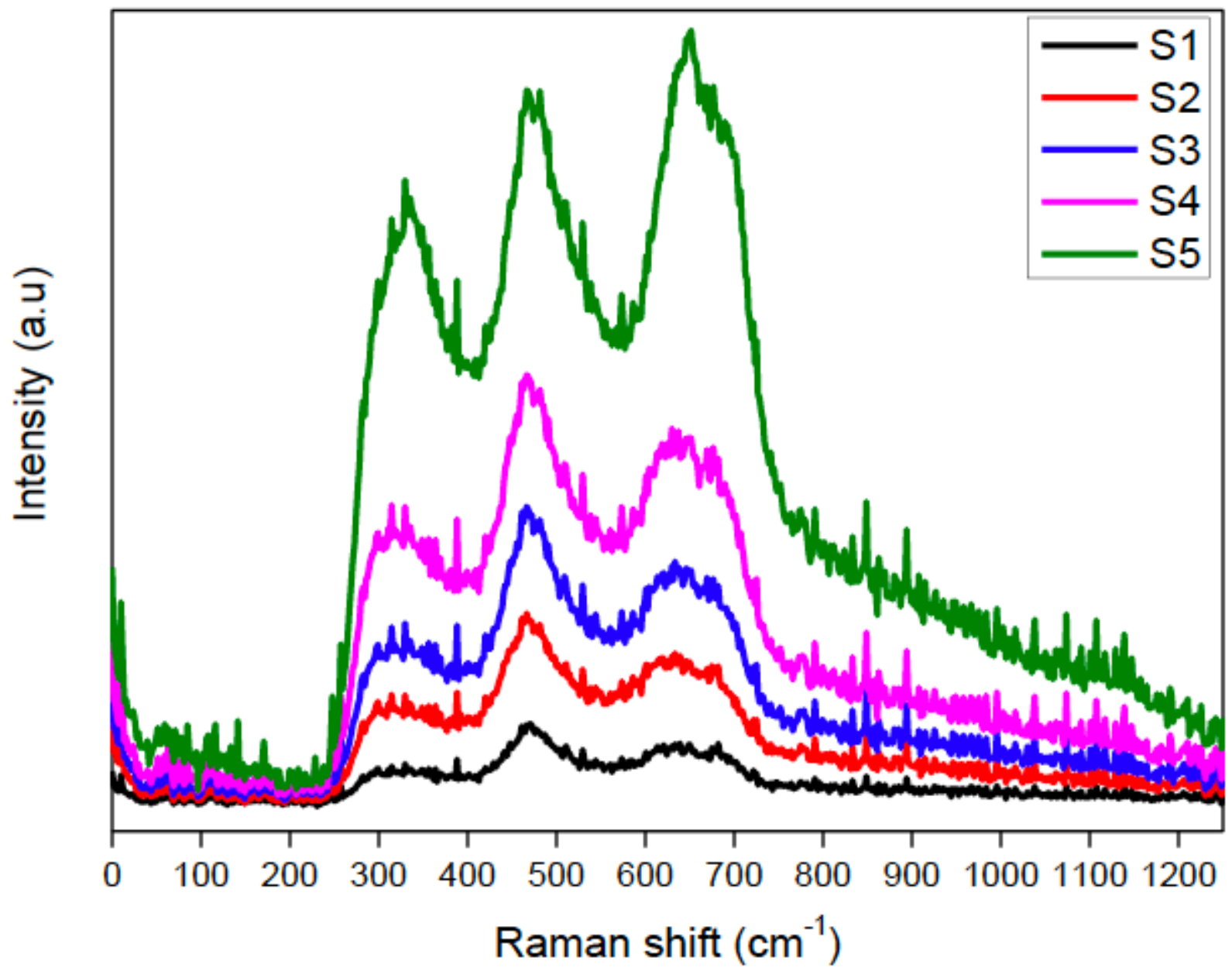

Figure 5

Raman spectra of for Zn0.4Co0.6-XMgXFe1.9La0.104 (X = 0.00, 0.15, 0.30, 0.45, 0.60) soft nanoferrites 


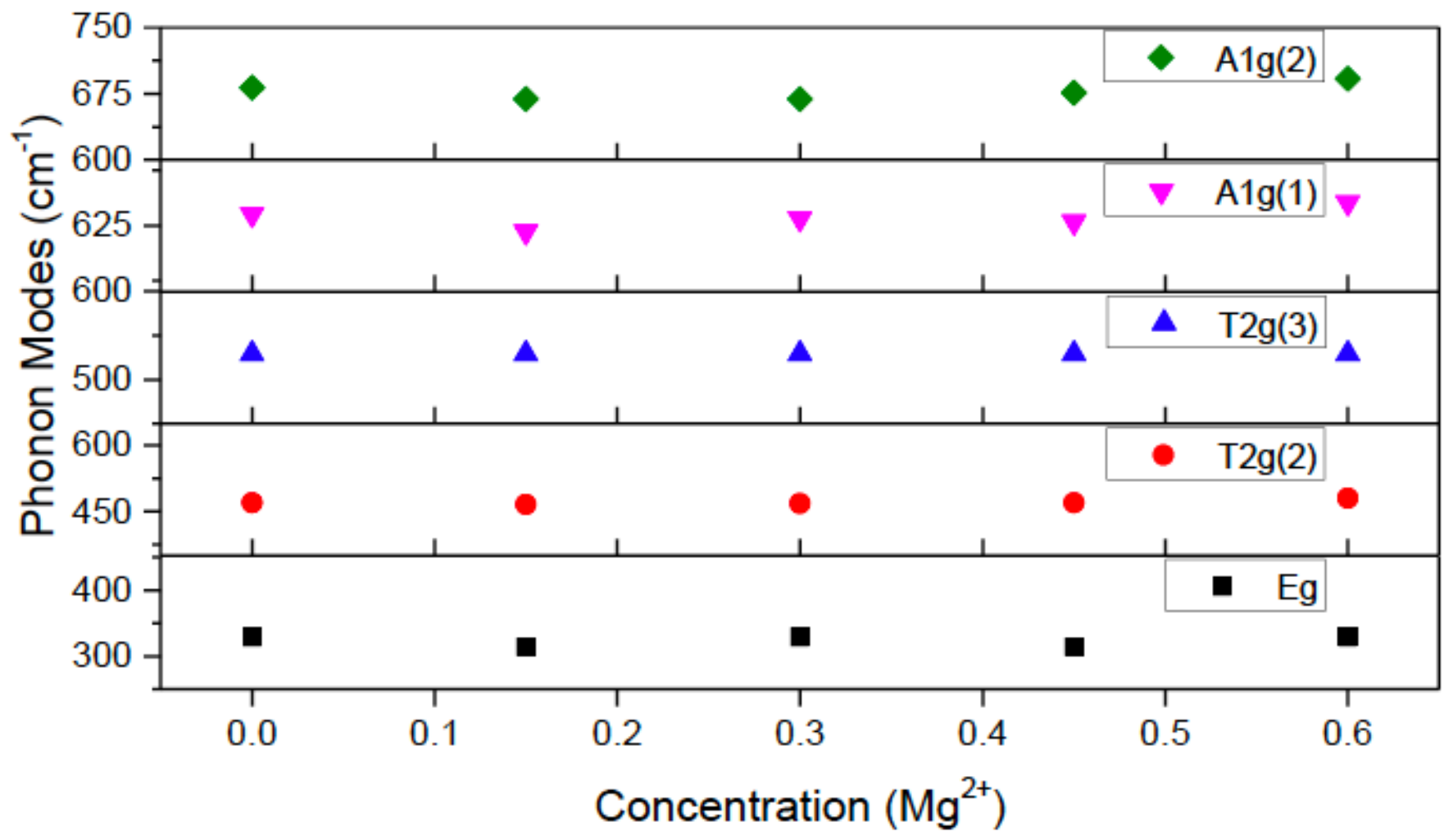

Figure 6

Observed Raman modes (cm-1) vs. concentration Mg2+ for X $=0.00-0.60$ 


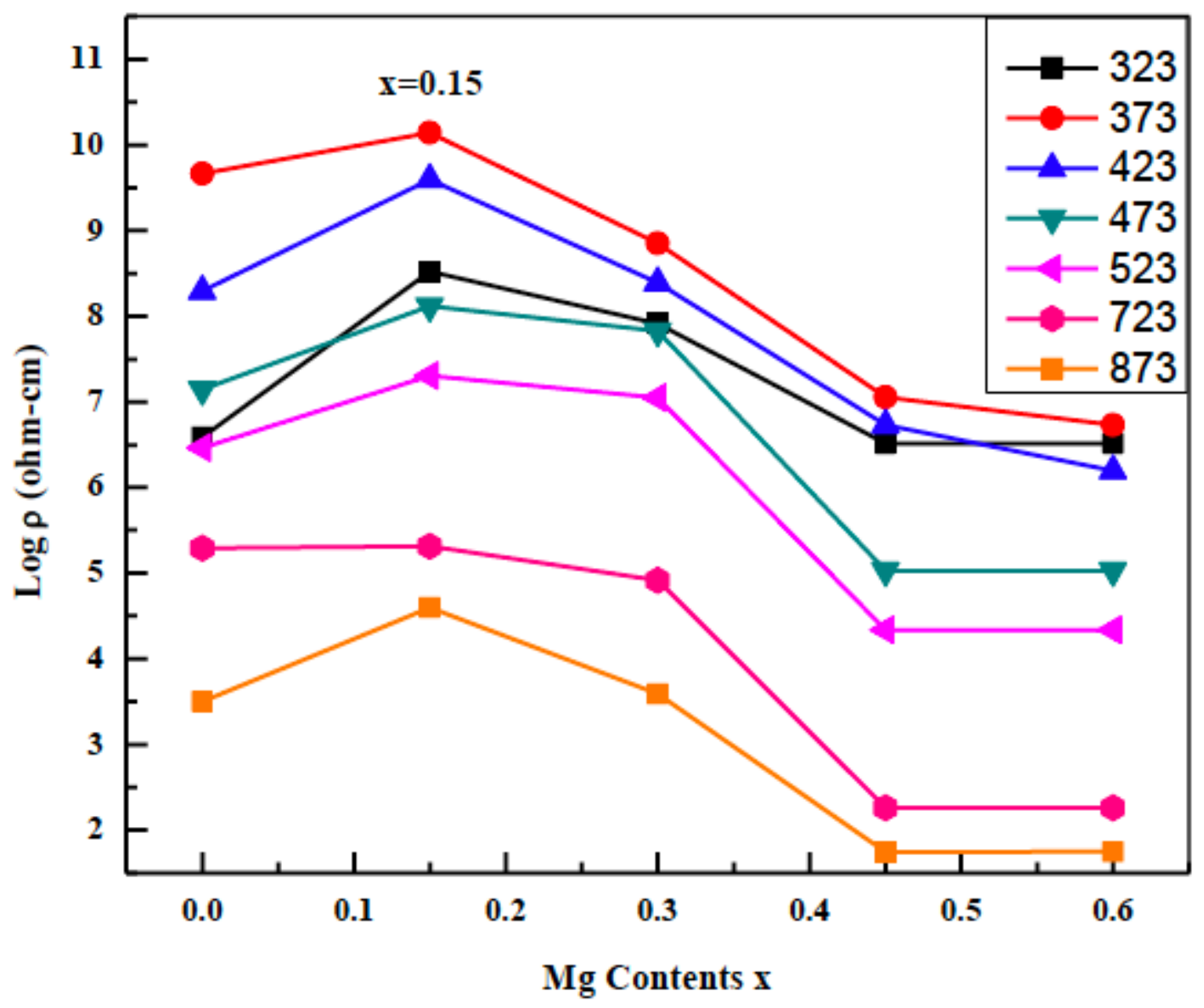

Figure 7

Log resistivity (ohm-cm) versus Mg2+ contents 


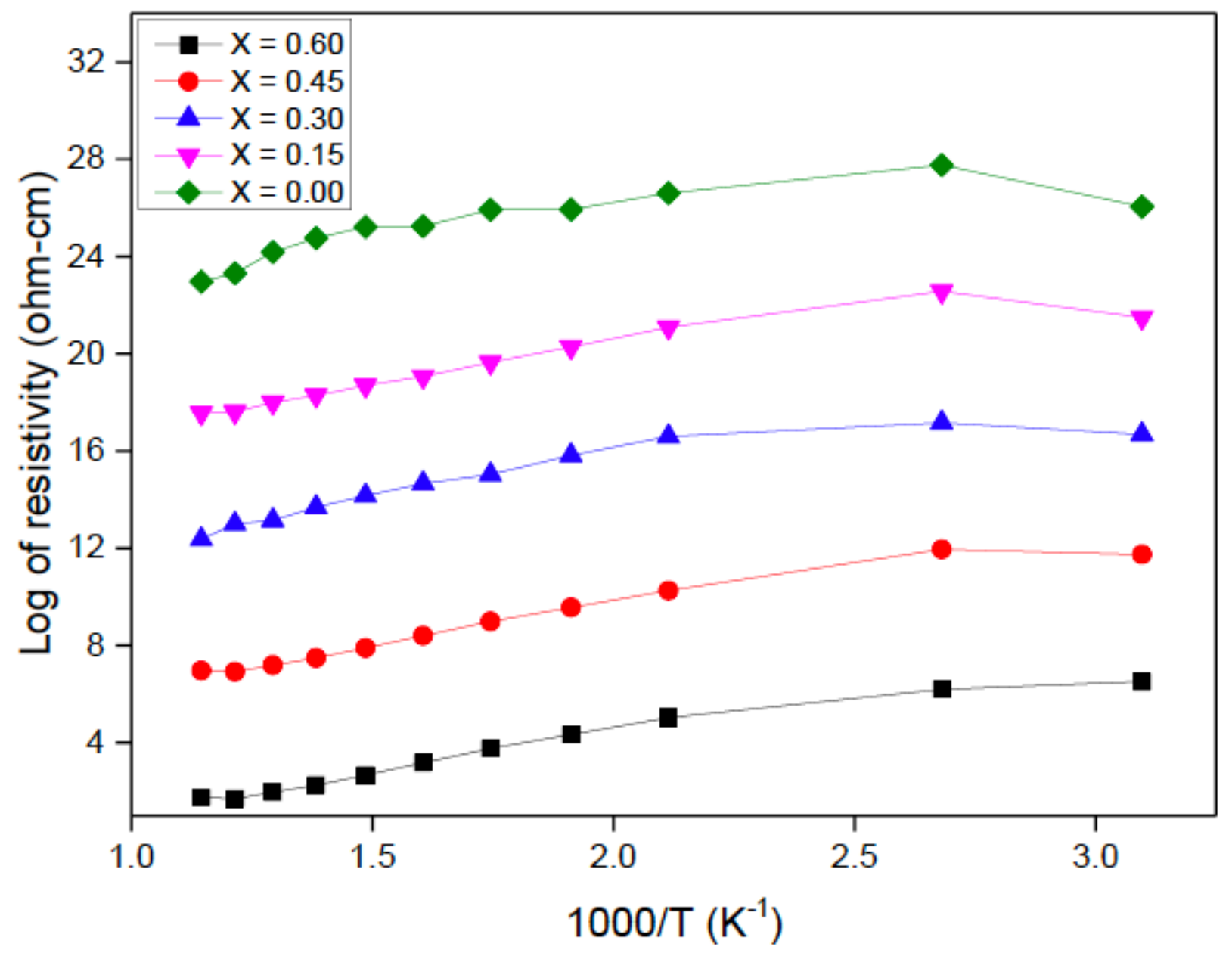

Figure 8

Resistivity trend as a function of 1000/T Zn0.4Co0.6-xMgxFe1.9La0.104 ( $\mathrm{X}=0.00,0.15,0.30,0.45,0.60)$. 


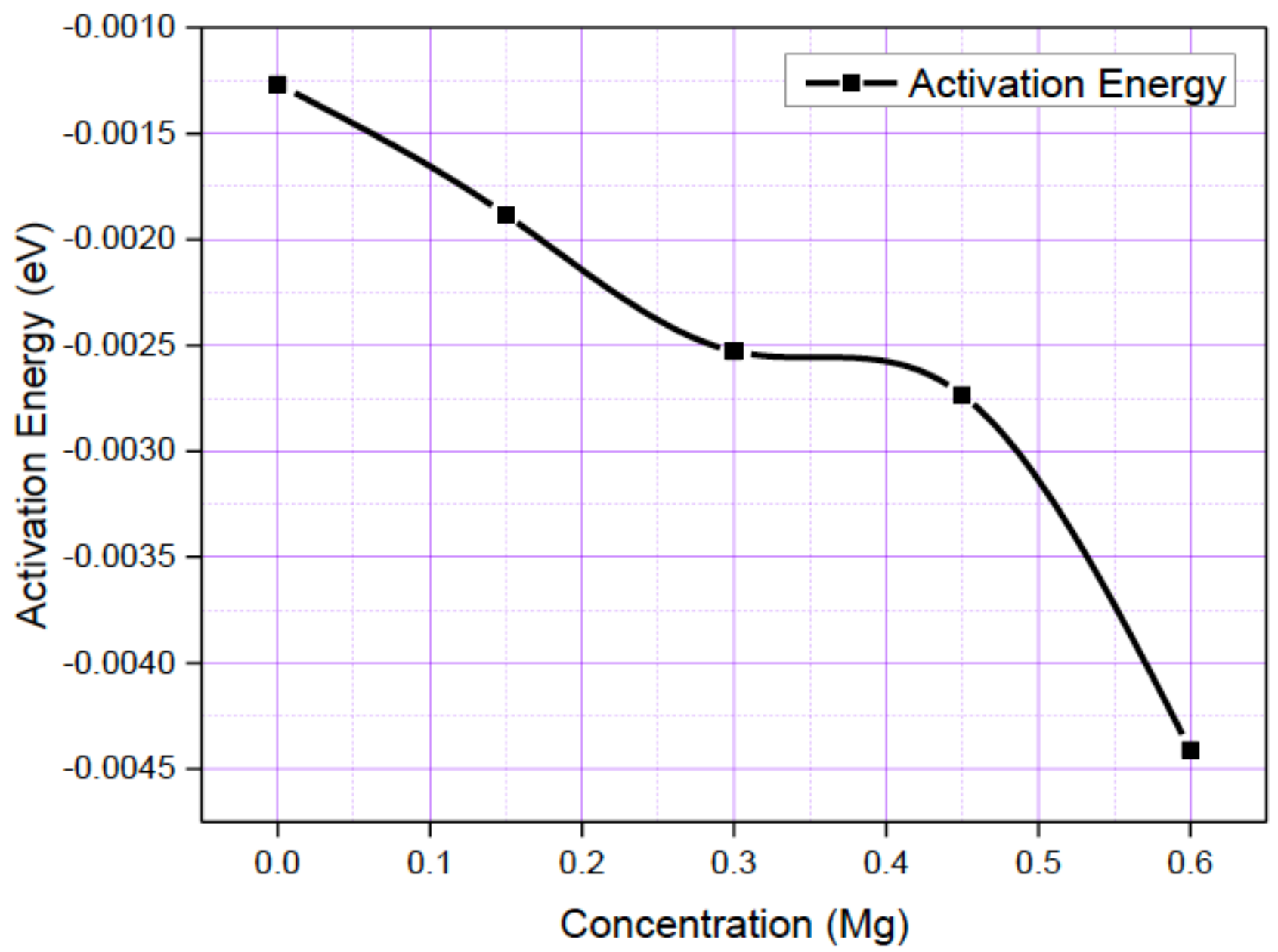

Figure 9

Activation energy (eV) versus concentration of Mg2+ for Zn0.4Co0.6-XMgXFe1.9La0.104 (X = 0.00, 0.15, $0.30,0.45,0.60)$ 


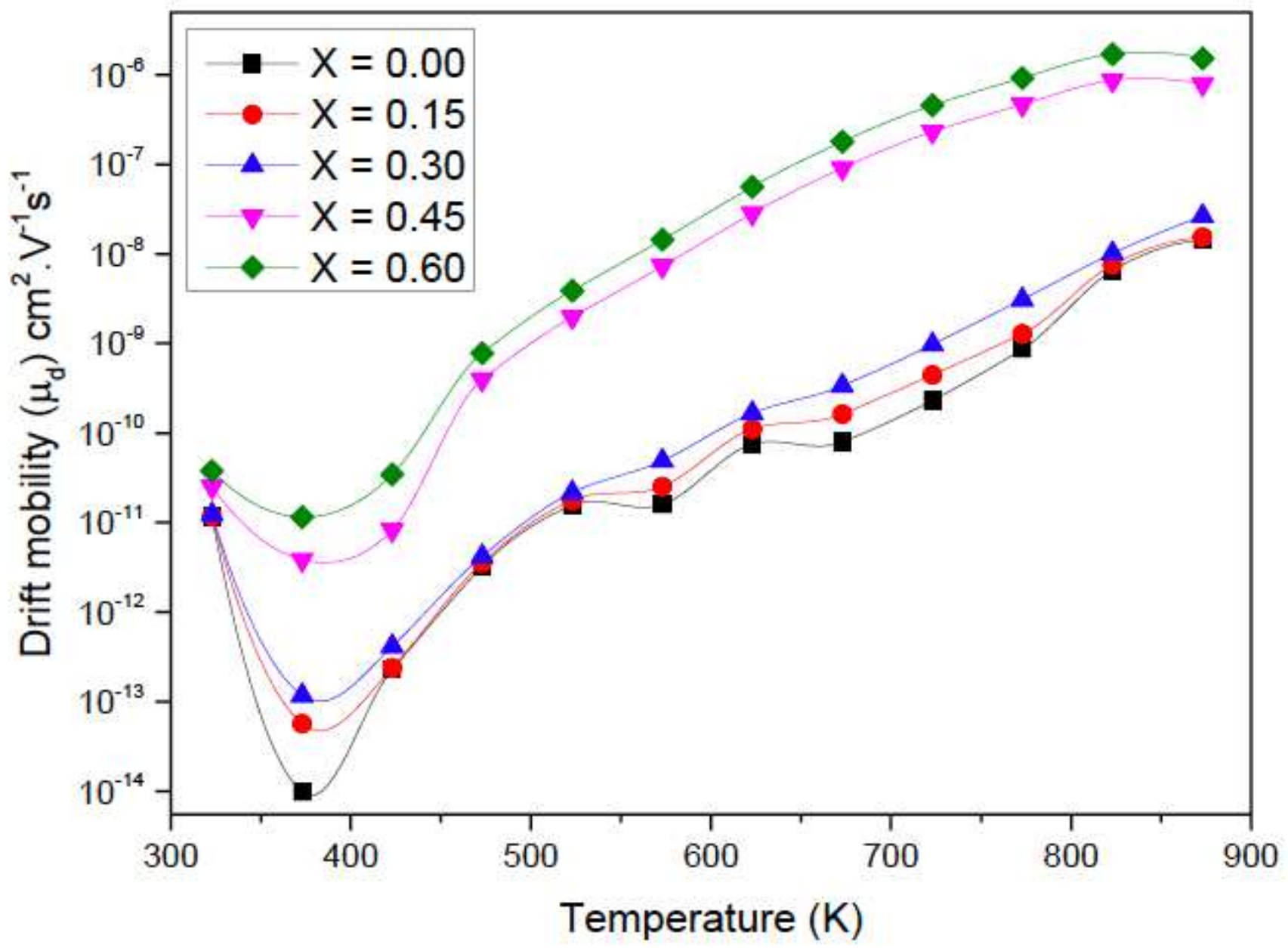

Figure 10

Relation between temperature $(K)$ and drift mobility $(\mu D C)$ for $X=0.00-0.60$ nanoferrites. 


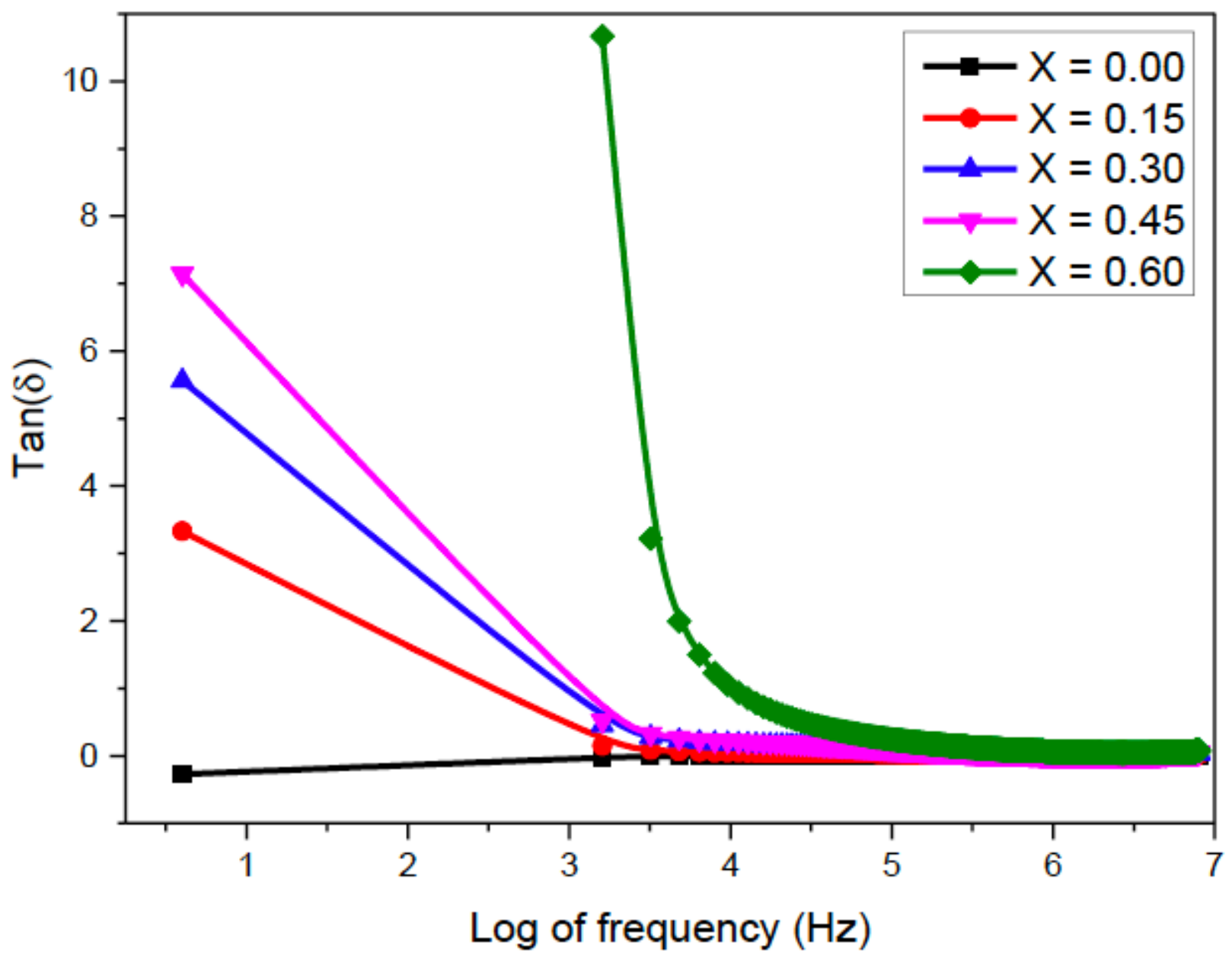

Figure 11

Dielectric loss ( $\tan \delta)$ of Zn0.4Co0.6-XMgXFe1.9La0.104 (X = 0.00, 0.15, 0.30, 0.45, 0.60) spinel ferrite 


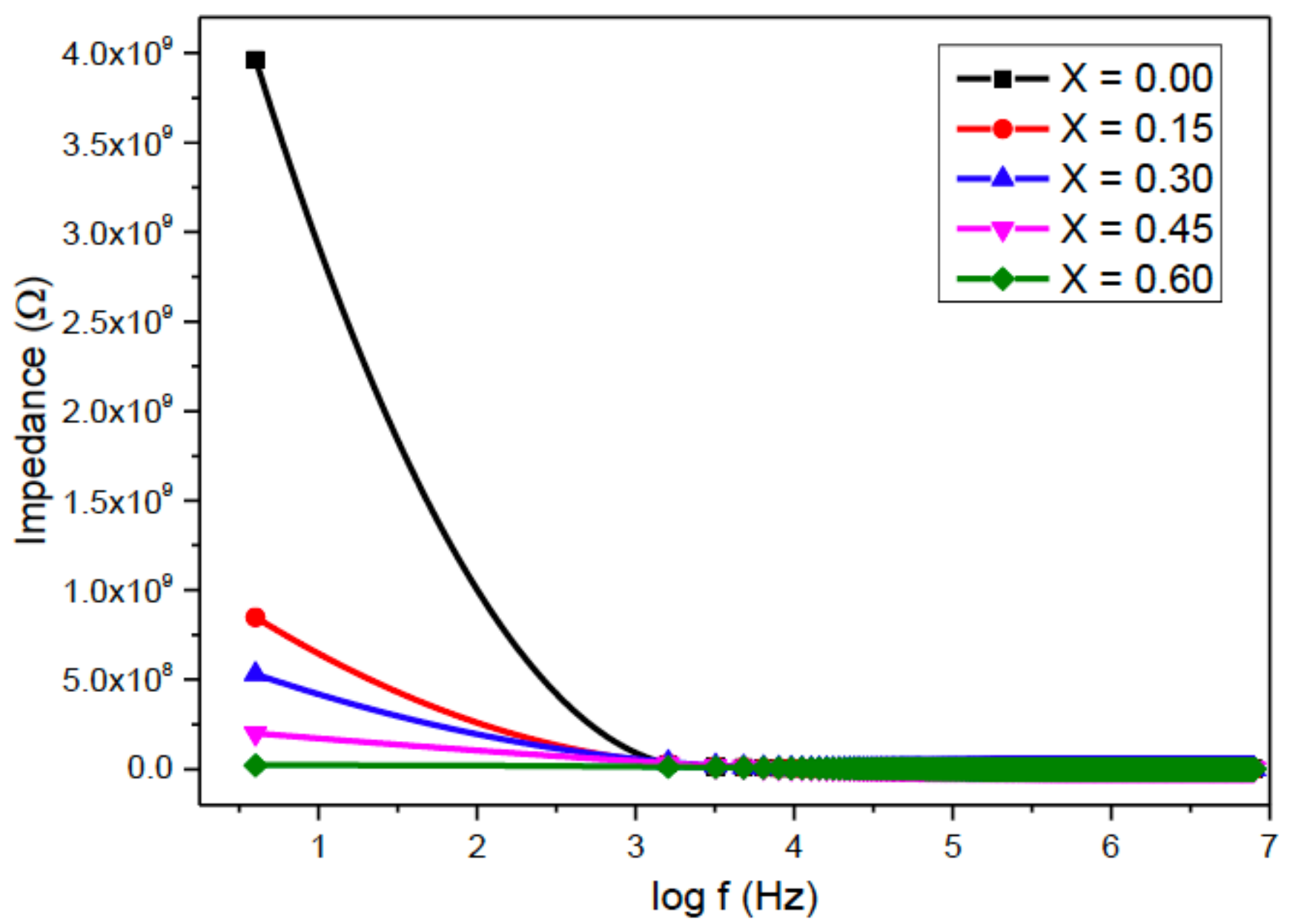

Figure 12

Impedance vs. log of frequency of Zn0.4Co0.6-XMgXFe1.9La0.104 (X = 0.00, 0.15, 0.30, 0.45, 0.60) spinel ferrite 


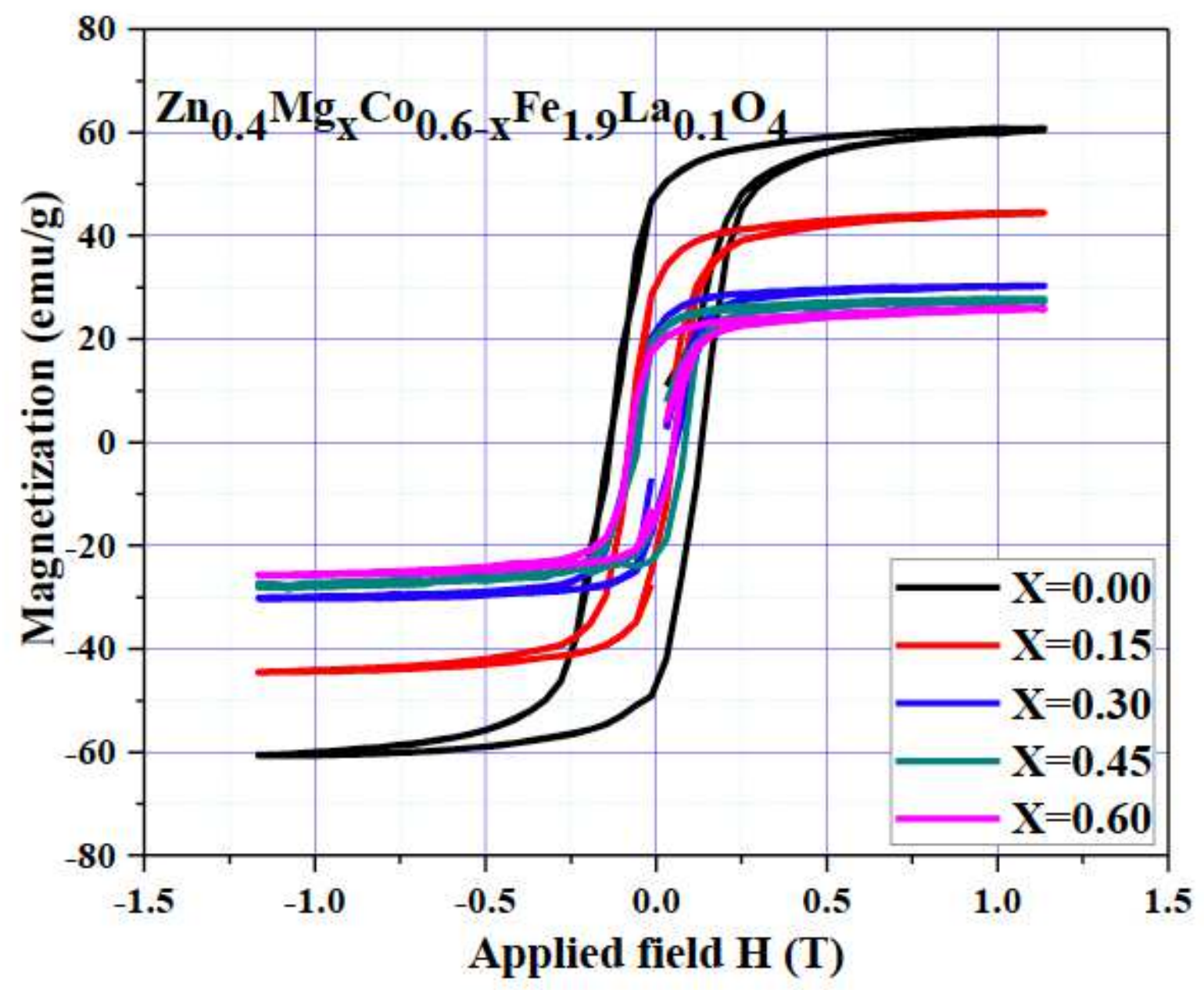

Figure 13

Concentrational dependence of magnetization in Zn0.4Co0.6-xMgxFe1.9La0.104 (X = 0.00, 0.15, 0.30, $0.45,0.60)$ spinel ferrite 


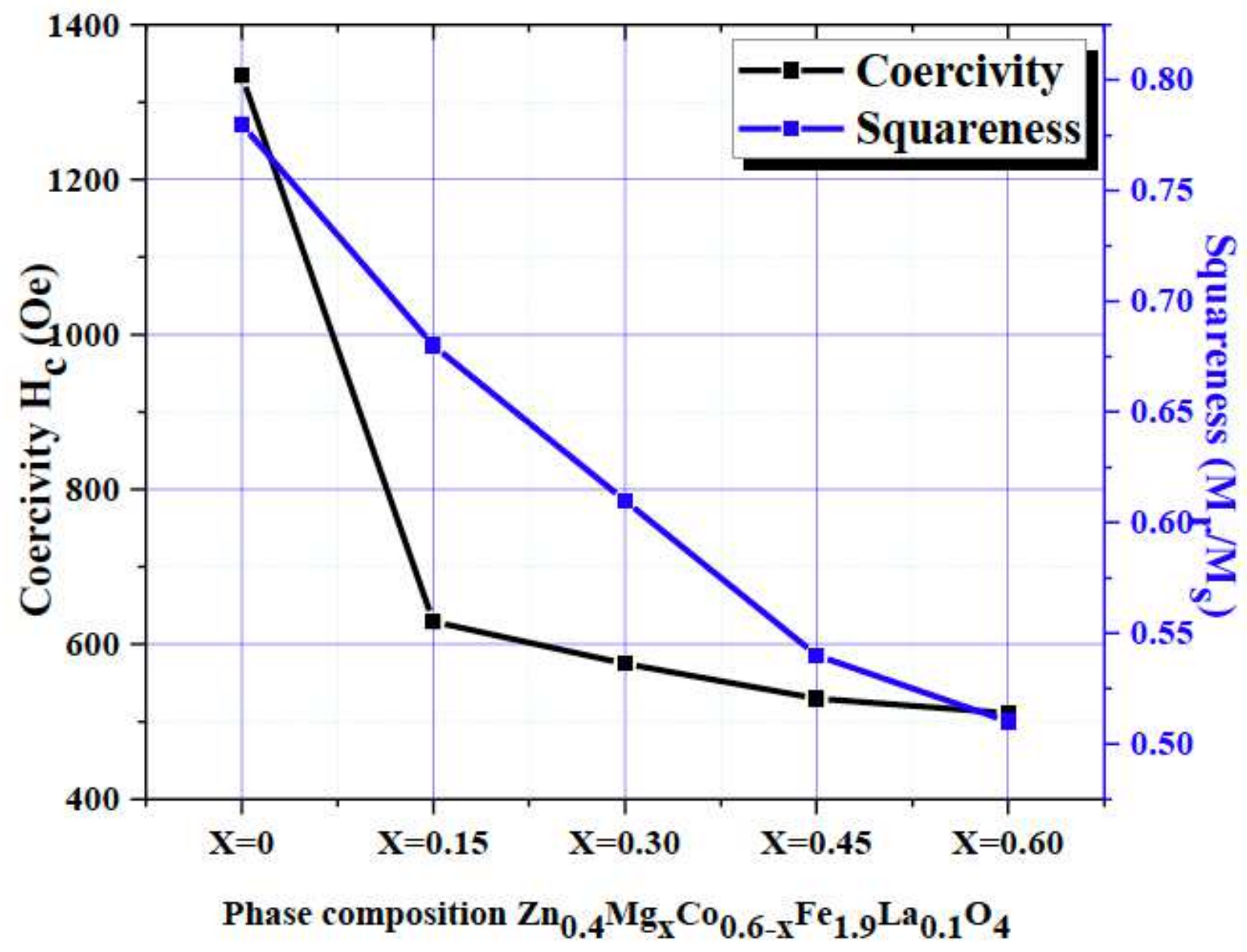

Figure 14

Variation in coercivity $(\mathrm{Hc})$ and remnant squareness (SQ) with the decrease in Co contents in Zn0.4Co0.6XMgXFe1.9La0.104 (X = 0.00, 0.15, 0.30, 0.45, 0.60) spinel ferrite 


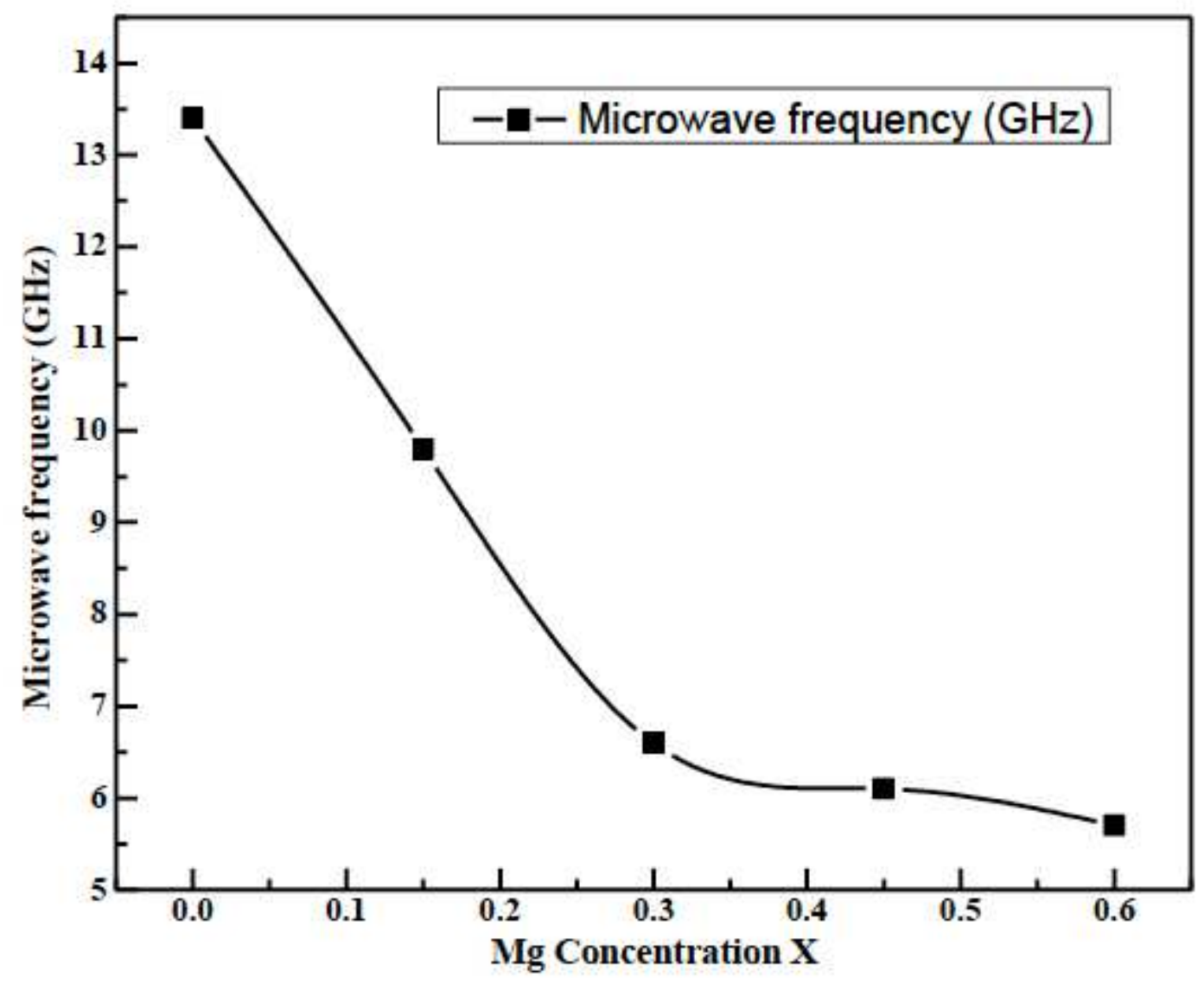

Figure 15

Variation in microwave frequency with the decrease in Co contents in Zn0.4Co0.6-XMgXFe1.9La0.104 (X $=0.00,0.15,0.30,0.45,0.60)$ spinel ferrite 